\title{
Determining attribute weights for multiple attribute decision analysis with discriminating power in belief distributions
}

DOI:

10.1016/j.knosys.2017.12.009

\section{Document Version}

Accepted author manuscript

Link to publication record in Manchester Research Explorer

Citation for published version (APA):

Fu, C., Xu, D. L., \& Xue, M. (2017). Determining attribute weights for multiple attribute decision analysis with discriminating power in belief distributions. Knowledge-Based Systems.

https://doi.org/10.1016/j.knosys.2017.12.009

Published in:

Knowledge-Based Systems

\section{Citing this paper}

Please note that where the full-text provided on Manchester Research Explorer is the Author Accepted Manuscript or Proof version this may differ from the final Published version. If citing, it is advised that you check and use the publisher's definitive version.

\section{General rights}

Copyright and moral rights for the publications made accessible in the Research Explorer are retained by the authors and/or other copyright owners and it is a condition of accessing publications that users recognise and abide by the legal requirements associated with these rights.

\section{Takedown policy}

If you believe that this document breaches copyright please refer to the University of Manchester's Takedown Procedures [http://man.ac.uk/04Y6Bo] or contact uml.scholarlycommunications@manchester.ac.uk providing relevant details, so we can investigate your claim.

\section{OPEN ACCESS}




\title{
Determining attribute weights for multiple attribute decision analysis
} with discriminating power in belief distributions

\author{
Chao $\mathrm{Fu}^{1,2, *}$, Dong-Ling $\mathrm{Xu}^{3}$, Min Xue $\mathrm{X}^{1,2}$ \\ ${ }^{1}$ School of Management, Hefei University of Technology, Hefei, Box 270, Hefei 230009, Anhui, \\ P.R. China \\ ${ }^{2}$ Key Laboratory of Process Optimization and Intelligent Decision-making, Ministry of \\ Education, Hefei 230009, Anhui, P.R. China \\ ${ }^{3}$ Decision and Cognitive Sciences Research Centre, Alliance Manchester Business School, \\ The University of Manchester, Manchester M13 9SS, UK
}

Abstract Attribute weight assignment plays an important role in multiple attribute decision analysis (MADA). When the performances of alternatives on each attribute are expressed by distributions instead of single values, how to use the differences in the performances to obtain attribute weights is an interesting but difficult issue. To address this issue, in this paper, we propose a method for obtaining attribute weights from discriminating power in belief distributions. With the consideration of the differences among the utilities of all assessment grades used to profile belief distributions, the dissimilarity based discriminating power, the standard deviation based discriminating power, and the Gini's mean difference based discriminating power of the performances of all alternatives on each attribute are constructed to determine three sets of respective weights of attributes. They are convexly combined using three coefficients to generate integrated weights of attributes. To relieve the burden on a decision maker to provide precise values for the three coefficients, they are allowed to change between 0 and 1 , as long as their sum is equal to 1 . Under such constraints on the three coefficients, an optimization model is constructed to determine the minimum and maximum expected utilities of each alternative. From the expected utilities, all alternatives are then compared using Hurwicz rule with the provided optimism degree interval to generate solutions to MADA problems. The transitivity of the comparison outcomes among three alternatives under a given optimism degree interval is theoretically analyzed to guarantee the rationality of the outcomes. A focal form selection problem is investigated to demonstrate the applicability and validity of the proposed method.

Keywords Multiple attribute decision analysis; Attribute weights; Transitivity; Belief distributions; Analytical algorithm

\footnotetext{
Corresponding author. Tel: 0086-551-62904930; fax: 0086-551-62905263.

E-mail address: wls_fuchao@163.com (C. Fu).
} 


\section{Introduction}

In existing studies, many different methods have been developed for multiple attribute decision analysis (MADA). Representative methods include multiple attribute utility function (MAUF) methods (Balla et al. 2014; Keeney and Raiffa 1993; Butler et al. 1997; Butler et al. 2001; Wakker et al. 2004), multiple attribute value function methods (Belton and Stewart 2002; Chin et al. 2015; Fischer 1995; Fu and Xu 2016; Fu et al. 2016; Kadziński et al. 2014; Keeney 2002; Lan et al. 2015; Zhang et al. 2017), outranking methods such as PROMETHEE methods (Chen 2014a; Miłosz and Krzysztof 2016) and ELECTRE methods (Chen 2014b; Corrente et al. 2016), and distance based methods such as the extensions of TOPSIS method (Baykasoğlu and Gölcük 2015; Wang et al. 2016) and VIKOR method (Qin et al. 2015; Madjid et al. 2016). One similarity among those different methods is that attribute weights are taken into account although the meanings of the weights may be different. Different sets of attribute weights may generate different solutions to a decision problem no matter whichever method is applied. For this reason, determining attribute weights is a common step in MADA methods.

To focus on how to determine attribute weights in MADA, different types of methods have been proposed in the literature. Some methods provide support for a decision marker to assign weights to attributes subjectively, which are called subjective methods. Representative methods include direct rating method (Bottomley and Doyle 2001; Roberts and Goodwin 2002), Delphi method (Hwang and Yoon 1981), eigenvector method (Saaty 1977; Takeda et al. 1987), point allocation method (Doyle et al. 1997; Roberts and Goodwin 2002), linear programming model (Horowitz and Zappe 1995), and goal programming model (Shirland et al. 2003).

Many other methods use the information in a decision matrix to determine attribute weights instead of requiring a decision maker to provide them, which are called objective methods. By following the idea that the amount of information or discriminating power contained in performances of alternatives on an attribute can reflect the weight of the attribute, many objective methods have been designed. Representative methods include standard deviation method (Deng et al. 2000), correlation coefficient and standard deviation integrated method (Wang and Luo 2010), criteria importance through intercriteria correlation method (Diakoulaki et al. 1995), entropy method (Chen and Li 2010, 2011; Deng et al. 2000; He et al. 2016), deviation maximization method (Şahin and Liu 2016; Wang 1998), and multiple objective programming model (Choo and Wedley 1985). In addition, there is another idea to derive the weight of each attribute by using the contribution of performances of alternatives on an attribute to some special quality of the solutions to the MADA problem, such as high 
solution reliability (Fu and $\mathrm{Xu} 2016$ ).

In some papers, subjective and objective methods are combined to generate attribute weights when a decision maker wishes to provide partial requirements for attribute weight assignment. This type of methods is referred to as integrated methods. In the integrated methods, the requirements for attribute weights are generally considered as constraints to be incorporated into objective methods (Fan et al. 2002; Ma et al. 1999; Wang and Parkan 2006; Chin et al. 2015; Fu and Wang 2015; Fu and Xu 2016; Pei 2013; Rao et al. 2011).

In a decision situation, a decision maker may prefer to use subjective methods to carry out attribute weight assignment when the decision maker can have his or her opinions about the weights. However, it is also known that different subjective methods may lead to different attribute weights, even if a decision maker has some opinions about the weights (Barron and Barrett 1996; Deng et al. 2000; Diakoulaki et al. 1995). Objective methods are useful when subjective preferences of the decision maker are fully or partially unavailable.

When single values are used to characterize the performances of alternatives on an attribute in MADA, it is easy to use objective methods to obtain attribute weights. On the condition that the performances of alternatives are expressed by belief distributions (see Section 2), however, the amount of discriminating power contained in the performances is difficult to measure. As such, it is challenging to use objective weight elicitation methods based on the discriminating power in this situation.

There are also two more issues related to the use of objective weight elicitation methods when the performances of alternatives are represented by belief distributions. One is the uncertainty in the weights and the second the uncertainty in the ranking of the alternatives due to the uncertainty (or unknowns) in the performances represented by belief distributions or performance distributions for short. The uncertainty in belief distributions (see Section 2) leads to the uncertainty in the calculated discriminating power and hence the attribute weights calculated using the discriminating power. The uncertainty in weights in turn leads to the second issue, the uncertain comparison outcomes and final ranking of alternatives.

For alternatives with uncertainty in their performances but their best and worst performance scores being known or obtainable, Hurwicz rule can be applied to rank them (Corrente et al. 2017; Jiang et al. 2015; Kleine 1999). To avoid the problem of comparison cycle and thus guarantee the validity of the comparison outcomes and ranking among alternatives, the transitivity of the ranking among alternatives (Yang et al. 2016) needs to be analyzed for the various values of optimism degree in Hurwicz rule. Or else, when alternative 1 is superior to alternative 2 and alternative 2 to alternative 3 judged by following Hurwicz principle with a specific value of optimism degree, it cannot be guaranteed that alternative 1 
is certainly superior to alternative 3 under the same conditions. If such comparison cycle occurs, decisions made based on the comparison outcomes will be questionable (Yang et al. 2016).

In this paper, we propose a method for obtaining attribute weights from the discriminating power contained in performances of alternatives profiled by belief distributions. In the method, three ways are developed to measure the discriminating power contained in the performances of all alternatives on an attribute. The first way is to construct a dissimilarity measure between two belief distributions, the second way to calculate the standard deviation of belief degrees on each grade in belief distributions, and the third way to calculate the Gini's mean difference (Kotz and Johnson 1982) of belief degrees on each grade in belief distributions. Correspondingly, three types of discriminating power on each attribute are obtained, which are the dissimilarity, the standard deviation, and the Gini's mean difference based discriminating power. Utilities of grades (see Section 2) are taken into account in the calculation of the three types of discriminating power to reflect the difference among grades. From the three types of discriminating power on each attribute, three sets of attribute weights are generated respectively. Then a set of integrated weights is obtained by linearly combining the three sets of weights using three non-negative coefficients, whose sum is equal to 1 . Suppose that the three coefficients of the three sets of attribute weights are variables. An optimization model is constructed based on the integrated weights of attributes to determine the minimum and maximum expected utilities of each alternative. Given the expected utility interval for each alternative, Hurwicz rule is applied to compare and rank alternatives and the preference relation between any two alternatives is theoretically analyzed and established for the whole value range of the optimism degree in Hurwicz rule which is from 0 to 1 . If the optimism degree is given as an interval instead of a single value, how to compare and rank alternatives based on the established preference relation is also given and the transitivity of such comparison outcomes is theoretically analyzed.

The rest of this paper is organized as follows. Section 2 presents the modeling of MADA problems by using belief distributions. Section 3 introduces the proposed method of obtaining attribute weights. In Section 4, a focal firm selection problem is investigated to demonstrate the applicability and validity of the proposed method. The paper is concluded in Section 5.

\section{Modeling of MADA problems using belief distributions}

Suppose that a MADA problem has $M$ alternatives denoted by $a_{l}(l=1, \ldots, M)$ and $L$ attributes denoted by $e_{i}(i=1, \ldots, L)$. Relative weights of the $L$ attributes are denoted by $w=$ $\left(w_{1}, w_{2}, \ldots, w_{L}\right)$ such that $0 \leq w_{i} \leq 1$ and $\sum_{i=1}^{L} w_{i}=1$.

Suppose that $\Omega=\left\{H_{1}, H_{2}, \ldots, H_{N}\right\}$ denotes a set of grades and the utilities of the grades 
$u\left(H_{n}\right)(n=1, \ldots, N)$ satisfy the constraint $0=u\left(H_{1}\right)<u\left(H_{2}\right)<\ldots<u\left(H_{N}\right)=1$ to reflect the difference among grades. The $M$ alternatives are assessed at the $L$ attributes by using $H_{n}(n=$ $1, \ldots, N)$. Let $\beta_{n, i}\left(a_{l}\right)$ denote the belief degree assigned to grade $H_{n}$ when alternative $a_{l}$ is assessed on attribute $e_{i}$. Then the assessment can be profiled by a belief distribution $B\left(e_{i}\left(a_{l}\right)\right)=$ $\left\{\left(H_{n}, \beta_{n, i}\left(a_{l}\right)\right), n=1, \ldots, N ;\left(\Omega, \beta_{\Omega, i}\left(a_{l}\right)\right)\right\}$, where $\beta_{n, i}\left(a_{l}\right) \geq 0, \quad \sum_{n=1}^{N} \beta_{n, i}\left(a_{l}\right) \leq 1$, and $\beta_{\Omega, i}\left(a_{l}\right)=1$

- $\sum_{n=1}^{N} \beta_{n, i}\left(a_{l}\right)$ represents the degree of global ignorance (Xu 2012; Yang and Xu 2013; Fu and Wang 2015). If $\beta_{\Omega, i}\left(a_{l}\right)=0$, the assessment is complete; otherwise, it is incomplete. When the belief distribution of each alternative on each attribute is given, a belief decision matrix $S_{L \times M}$ is formed. Note that because the degree of global ignorance could be assigned to any grades, its impact needs to be analyzed in MADA.

To generate a solution, the individual assessments $B\left(e_{i}\left(a_{l}\right)\right)(i=1, \ldots, L)$ weighted by their respective weights are combined to generate the overall assessment $B\left(y\left(a_{l}\right)\right)=\left\{\left(H_{n}, \beta_{n}\left(a_{l}\right)\right), n\right.$ $\left.=1, \ldots, N ;\left(\Omega, \beta_{\Omega}\left(a_{l}\right)\right)\right\}$, where $\beta_{\Omega}\left(a_{l}\right)$ represents the degree of aggregated global ignorance. Based on the overall assessment, the utilities of grades $u\left(H_{n}\right)(n=1, \ldots, N)$ are used to produce the minimum and maximum expected utilities of alternative $a_{l}$, i.e., $u^{-}\left(a_{l}\right)=$ $\sum_{n=2}^{N} \beta_{n}\left(a_{l}\right) \cdot u\left(H_{n}\right)+\left(\beta_{1}\left(a_{l}\right)+\beta_{\Omega}\left(a_{l}\right)\right) \cdot u\left(H_{1}\right) \quad$ and $\quad u^{+}\left(a_{l}\right)=\sum_{n=1}^{N-1} \beta_{n}\left(a_{l}\right) \cdot u\left(H_{n}\right)+\left(\beta_{N}\left(a_{l}\right)+\right.$ $\left.\beta_{\Omega}\left(a_{l}\right)\right) \cdot u\left(H_{N}\right)$ with $0 \leq u^{-}\left(a_{l}\right) \leq u^{+}\left(a_{l}\right) \leq 1$. The expected utilities are then used to compare alternatives with the help of a decision rule consistent with the preferences of the decision maker, such as Hurwicz rule.

What presented above is also called the evidential reasoning (ER) approach, which is a type of MAUF method (Wang et al. 2006b; Yang 2001; Yang et al. 2006; Fu et al. 2015).

\section{Proposed method}

In MADA, attribute weights play an important role in characterizing how the performance of an alternative on an attribute affects the overall performance in comparison with other attributes. On the assumption that there is flexibility in attribute weight assignment, we propose a method to determine attribute weights for finding solutions to MADA problems which are modeled by using belief distributions. The process of how to determine attribute weights and the process of how to find solutions based on the attribute weights with the help of Hurwicz rule are given in details in this section.

\subsection{Determination of attribute weights}

In the proposed method, the amount of information or discriminating power contained in the performances of alternatives on each attribute is adopted to determine attribute weights.

As shown in Section 2, the assessment of an alternative's performance is profiled by a belief distribution rather than a precise number. Without loss of generality, we assume that the 
grades $H_{n}(n=1, \ldots, N)$ used to profile such an assessment satisfy the constraint $0=u\left(H_{1}\right)<$ $u\left(H_{2}\right)<\ldots<u\left(H_{N}\right)=1$, which means that they are arranged in order of preferences from worst to best. In this situation, the dissimilarity measure between two assessments developed by $\mathrm{Fu}$ et al. (2015) can be used to measure the discriminating power contained in performances of alternatives on an attribute.

Definition 1. Suppose that the distributed dissimilarity between two assessments $B\left(e_{i}\left(a_{l}\right)\right)$ and $B\left(e_{i}\left(a_{m}\right)\right)$ represented by $G D\left(e_{i}\left(a_{l m}\right)\right)$ is defined as

$$
\begin{aligned}
& G D\left(e_{i}\left(a_{l m}\right)\right)=\left(\bar{\beta}_{1, i}\left(a_{l m}\right), \ldots, \bar{\beta}_{n, i}\left(a_{l m}\right), \ldots, \bar{\beta}_{N, i}\left(a_{l m}\right)\right)= \\
& \left(\left|\beta_{1, i}\left(a_{l}\right)-\beta_{1, i}\left(a_{m}\right)\right|, \ldots,\left|\beta_{n, i}\left(a_{l}\right)-\beta_{n, i}\left(a_{m}\right)\right|, \ldots,\left|\beta_{N, i}\left(a_{l}\right)-\beta_{N, i}\left(a_{m}\right)\right|\right) .
\end{aligned}
$$

Then, a dissimilarity measure between the two assessments is constructed using $G D\left(e_{i}\left(a_{l m}\right)\right)$ as

$$
D\left(e_{i}\left(a_{l m}\right)\right)=\sum_{n=1}^{N-1} \sum_{o=n+1}^{N} \bar{\beta}_{n, i}\left(a_{l m}\right) \cdot \bar{\beta}_{o, i}\left(a_{l m}\right) \cdot\left(u\left(H_{o}\right)-u\left(H_{n}\right)\right) .
$$

Through using the dissimilarity measure between two assessments, the discriminating power on an attribute can be measured.

Definition 2. Suppose that the dissimilarity between any two assessments $B\left(e_{i}\left(a_{l}\right)\right)$ and $B\left(e_{i}\left(a_{m}\right)\right)$ is measured by using Definition 1 . Then, the average dissimilarity between the assessment $B\left(e_{i}\left(a_{l}\right)\right)$ and any other assessments $B\left(e_{i}\left(a_{m}\right)\right)(m \neq l)$ is defined as

$$
\bar{D}\left(e_{i}\left(a_{l}\right)\right)=\frac{\sum_{m=1, m \neq l}^{M} D\left(e_{i}\left(a_{l m}\right)\right)}{M-1},
$$

and the discriminating power on attribute $e_{i}$ is further defined as

$$
\bar{D}\left(e_{i}\right)=\frac{\sum_{l=1}^{M} \bar{D}\left(e_{i}\left(a_{l}\right)\right)}{M} .
$$

As the discriminating power in Eq. (4) is generated based on the dissimilarity between two assessments, it is called the dissimilarity based discriminating power. In addition to such discriminating power, there are two other ways to measure the discriminating power on attribute $e_{i}$. In the second way, standard deviation (SD) of belief degrees of assessments on each grade is calculated and combined with utilities of grades to characterize the discriminating power on attribute $e_{i}$.

Definition 3. Given assessments $B\left(e_{i}\left(a_{l}\right)\right)(l=1, \ldots, M)$, the SD of belief degrees $\beta_{n, i}\left(a_{l}\right)(l=$ $1, \ldots, M)$ on grade $H_{n}$ is defined as

$$
\bar{S}_{n}\left(e_{i}\right)=\sqrt{\frac{1}{M-1} \sum_{l=1}^{M}\left(\beta_{n, i}\left(a_{l}\right)-\bar{\beta}_{n, i}\right)^{2}}
$$


where $\bar{\beta}_{n, i}=\frac{\sum_{l=1}^{M} \beta_{n, i}\left(a_{l}\right)}{M}$ represents the mean of belief degrees $\beta_{n, i}\left(a_{l}\right)(l=1, \ldots, M)$ on grade $H_{n}$. Then, the discriminating power on attribute $e_{i}$ is measured using $\bar{S}_{n}\left(e_{i}\right)$ by

$$
\bar{S}\left(e_{i}\right)=\sum_{n=1}^{N-1} \sum_{o=n+1}^{N} \bar{S}_{n}\left(e_{i}\right) \cdot \bar{S}_{o}\left(e_{i}\right) \cdot\left(u\left(H_{o}\right)-u\left(H_{n}\right)\right) .
$$

The discriminating power on attribute $e_{i}$ in Eq. (6) is generated based on the SD of belief degrees of assessments on each grade and thus named as the SD based discriminating power. Its construction is inspired by the idea of the dissimilarity measure between two assessments in Definition 1. In addition to the above two ways, the third way to measure the discriminating power on attribute $e_{i}$ is developed based on Gini's mean difference (GMD) (Kotz and Johnson 1982). The GMD of belief degrees of assessments on each grade is calculated and combined with utilities of grades to characterize the discriminating power on attribute $e_{i}$.

Definition 4. Given assessments $B\left(e_{i}\left(a_{l}\right)\right)(l=1, \ldots, M)$, the GMD of belief degrees $\beta_{n, i}\left(a_{l}\right)(l$ $=1, \ldots, M)$ on grade $H_{n}$ is defined as

$$
\bar{G}_{n}\left(e_{i}\right)=\frac{1}{M^{2}-M} \sum_{l=1}^{M} \sum_{m=1}^{M}\left|\beta_{n, i}\left(a_{l}\right)-\beta_{n, i}\left(a_{m}\right)\right| .
$$

Then, the discriminating power on attribute $e_{i}$ is measured using $\bar{G}_{n}\left(e_{i}\right)$ by

$$
\bar{G}\left(e_{i}\right)=\sum_{n=1}^{N-1} \sum_{o=n+1}^{N} \bar{G}_{n}\left(e_{i}\right) \cdot \bar{G}_{o}\left(e_{i}\right) \cdot\left(u\left(H_{o}\right)-u\left(H_{n}\right)\right) .
$$

Similar to the first two ways, the discriminating power contained in attribute $e_{i}$ in Eq. (8) is called the GMD based discriminating power.

What discussed above is on the assumption that all assessments are complete. In a general case, there can be some incomplete assessments on each attribute. Under the conditions, $\beta_{n, i}\left(a_{l}\right)$ becomes a variable denoted by $\beta_{n, i}^{*}\left(a_{l}\right)$, which is limited to $\left[\beta_{n, i}\left(a_{l}\right), \beta_{n, i}\left(a_{l}\right)+\beta_{\Omega, i}\left(a_{l}\right)\right]$ due to the fact that there is no prior knowledge on how to allocate $\beta_{\Omega, i}\left(a_{l}\right)$, but the constraint on $\beta_{n, i}^{*}\left(a_{l}\right)$, i.e., $\sum_{n=1}^{N} \beta_{n, i}^{*}\left(a_{l}\right)=1$ needs to be satisfied as $\beta_{n, i}^{*}\left(a_{l}\right)$ are probabilities by nature. All constraints on $\beta_{n, i}^{*}\left(a_{l}\right)$ generate a region. Let us analyze the features of this region. Given $\delta$ such that $0 \leq \delta \leq 1$ and any two belief distributions $\left\{\left(H_{n}, \beta_{n, i}^{1}\left(a_{l}\right)\right), n=1, \ldots, N\right\}$ and $\left\{\left(H_{n}, \quad \beta_{n, i}^{2}\left(a_{l}\right)\right), n=1, \ldots, N\right\}$ in the region, it can be found that $\beta_{n, i}\left(a_{l}\right) \leq$ $\delta \cdot \beta_{n, i}^{1}\left(a_{l}\right)+(1-\delta) \cdot \beta_{n, i}^{2}\left(a_{l}\right) \leq \beta_{n, i}\left(a_{l}\right)+\beta_{\Omega, i}\left(a_{l}\right)$ and $\sum_{n=1}^{N} \delta \cdot \beta_{n, i}^{1}\left(a_{l}\right)+(1-\delta) \cdot \beta_{n, i}^{2}\left(a_{l}\right)=1$. From 
this we recognize that the constraints are convex and form a bounded closed domain. Meanwhile, Definitions 1-4 show that $\bar{D}\left(e_{i}\right), \bar{S}\left(e_{i}\right)$, and $\bar{G}\left(e_{i}\right)$ can be seen as continuous functions of $M \cdot N$ variables, as demonstrated below.

Theorem 1. (Nikolsky 1977) If a function of multiple variables is formed by a finite number of operations, including addition (sum), subtraction (difference), multiplication (product), division (quotient) without a zero-valued denominator and composition on continuous functions of multiple variables on a bounded closed set, then it is continuous.

Theorem 2. (Nikolsky 1977) Suppose that $f$ is a continuous function of multiple variables on a bounded closed set. Then,

(1) its minimum and maximum values on that set can be reached, and

(2) any point between the minimum and maximum values on that set can be reached.

When there are some incomplete assessments on each attribute, Theorems 1 and 2 indicate that $\bar{D}\left(e_{i}\right), \bar{S}\left(e_{i}\right)$, and $\bar{G}\left(e_{i}\right)$ become intervals denoted by $\left[\bar{D}^{-}\left(e_{i}\right), \bar{D}^{+}\left(e_{i}\right)\right],\left[\bar{S}^{-}\left(e_{i}\right)\right.$, $\left.\bar{S}^{+}\left(e_{i}\right)\right]$, and $\left[\bar{G}^{-}\left(e_{i}\right), \bar{G}^{+}\left(e_{i}\right)\right]$, respectively. In each of the three intervals, each point may be possible to occur. The following three pairs of optimization problems are constructed to determine the three intervals.

MIN/MAX $\quad \bar{D}\left(e_{i}\right)$

s.t. $\quad \beta_{n, i}\left(a_{l}\right) \leq \beta_{n, i}^{*}\left(a_{l}\right) \leq \beta_{n, i}\left(a_{l}\right)+\beta_{\Omega, i}\left(a_{l}\right), n=1, \ldots, N, l=1, \ldots, M$,

$\sum_{n=1}^{N} \beta_{n, i}^{*}\left(a_{l}\right)=1, l=1, \ldots, M$.

MIN/MAX $\bar{S}\left(e_{i}\right)$

s.t. $\quad \beta_{n, i}\left(a_{l}\right) \leq \beta_{n, i}^{*}\left(a_{l}\right) \leq \beta_{n, i}\left(a_{l}\right)+\beta_{\Omega, i}\left(a_{l}\right), n=1, \ldots, N, l=1, \ldots, M$,

$$
\sum_{n=1}^{N} \beta_{n, i}^{*}\left(a_{l}\right)=1, l=1, \ldots, M
$$

MIN/MAX $\bar{G}\left(e_{i}\right)$

$$
\begin{array}{ll}
\text { s.t. } & \beta_{n, i}\left(a_{l}\right) \leq \beta_{n, i}^{*}\left(a_{l}\right) \leq \beta_{n, i}\left(a_{l}\right)+\beta_{\Omega, i}\left(a_{l}\right), n=1, \ldots, N, l=1, \ldots, M, \\
& \sum_{n=1}^{N} \beta_{n, i}^{*}\left(a_{l}\right)=1, l=1, \ldots, M .
\end{array}
$$

By following the idea that an attribute containing a larger amount of discriminating power should be assigned a larger weight, from $\left[\bar{D}^{-}\left(e_{i}\right), \bar{D}^{+}\left(e_{i}\right)\right]$ the weight of each attribute can be proportionally determined by the following pair of optimization problems. 


$$
\begin{aligned}
& \text { MIN/MAX } w_{i}^{d}=\frac{\bar{D}^{*}\left(e_{i}\right)}{\sum_{j=1}^{L} \bar{D}^{*}\left(e_{j}\right)} \\
& \text { s.t. } \quad \bar{D}^{-}\left(e_{i}\right) \leq \bar{D}^{*}\left(e_{i}\right) \leq \bar{D}^{+}\left(e_{i}\right), i=1, \ldots, L .
\end{aligned}
$$

In the pair of optimization problems, $\bar{D}^{*}\left(e_{i}\right)$ represents decision variable. Suppose that the minimum and maximum values of $w_{i}^{d}$ are denoted by $w_{i}^{d-}$ and $w_{i}^{d+}$, respectively. They can be analytically determined with the help of the following theorem.

Theorem 3. Suppose that $\left[\bar{D}^{-}\left(e_{i}\right), \bar{D}^{+}\left(e_{i}\right)\right](i=1, \ldots, L)$ is obtained from solving the pair of optimization problems in Eqs. (9)-(11) and $\bar{D}^{*}\left(e_{i}\right)$ is a variable limited to $\left[\bar{D}^{-}\left(e_{i}\right), \bar{D}^{+}\left(e_{i}\right)\right]$. Then, $w_{i}^{d}=\frac{\bar{D}^{*}\left(e_{i}\right)}{\sum_{j=1}^{L} \bar{D}^{*}\left(e_{j}\right)}$ is increasing with respect to $\bar{D}^{*}\left(e_{i}\right)$ and decreasing with respect to $\bar{D}^{*}\left(e_{j}\right) \quad(j \neq i)$.

Theorem 3 is proven in Appendix. In accordance with Theorem 3, $w_{i}^{d-}$ and $w_{i}^{d+}$ can be analytically determined as follows:

$$
\begin{aligned}
& w_{i}^{d-}=\frac{\bar{D}^{-}\left(e_{i}\right)}{\bar{D}^{-}\left(e_{i}\right)+\sum_{j=1, j \neq i}^{L} \bar{D}^{+}\left(e_{j}\right)}, \text { and } \\
& w_{i}^{d+}=\frac{\bar{D}^{+}\left(e_{i}\right)}{\bar{D}^{+}\left(e_{i}\right)+\sum_{j=1, j \neq i}^{L} \bar{D}^{-}\left(e_{j}\right)} .
\end{aligned}
$$

In a similar way, interval-valued weights of attributes $\left[w_{i}^{s-}, w_{i}^{s+}\right]$ from $\left[\bar{S}^{-}\left(e_{i}\right), \bar{S}^{+}\left(e_{i}\right)\right]$ and $\left[w_{i}^{g-}, w_{i}^{g+}\right]$ from $\left[\bar{G}^{-}\left(e_{i}\right), \bar{G}^{+}\left(e_{i}\right)\right]$ can be analytically determined by

$$
\begin{aligned}
w_{i}^{s-} & =\frac{\bar{S}^{-}\left(e_{i}\right)}{\bar{S}^{-}\left(e_{i}\right)+\sum_{j=1, j \neq i}^{L} \bar{S}^{+}\left(e_{j}\right)}, \\
w_{i}^{s+} & =\frac{\bar{S}^{+}\left(e_{i}\right)}{\bar{S}^{+}\left(e_{i}\right)+\sum_{j=1, j \neq i}^{L} \bar{S}^{-}\left(e_{j}\right)}, \\
w_{i}^{g-} & =\frac{\bar{G}^{-}\left(e_{i}\right)}{\bar{G}^{-}\left(e_{i}\right)+\sum_{j=1, j \neq i}^{L} \bar{G}^{+}\left(e_{j}\right)}, \text { and } \\
w_{i}^{g+} & =\frac{\bar{G}^{+}\left(e_{i}\right)}{\bar{G}^{+}\left(e_{i}\right)+\sum_{j=1, j \neq i}^{L} \bar{G}^{-}\left(e_{j}\right)} .
\end{aligned}
$$


Based on $\left[w_{i}^{d-}, w_{i}^{d+}\right],\left[w_{i}^{s-}, w_{i}^{s+}\right]$, and $\left[w_{i}^{g-}, w_{i}^{g+}\right]$, the integrated weights of attributes are defined as the weighted combination of $w_{i}^{d}, w_{i}^{s}$, and $w_{i}^{g}$ with three coefficients $\theta_{d}, \theta_{s}$, and $\theta_{g}$, i.e.,

$$
\bar{w}_{i}=\theta_{d} \cdot w_{i}^{d}+\theta_{s} \cdot w_{i}^{s}+\theta_{g} \cdot w_{i}^{g},
$$

where $0 \leq \theta_{d} \leq 1,0 \leq \theta_{s} \leq 1,0 \leq \theta_{g} \leq 1, \theta_{d}+\theta_{s}+\theta_{g}=1$, and $w_{i}^{d}, w_{i}^{s}$, and $w_{i}^{g}$ limited to $\left[w_{i}^{d-}, w_{i}^{d+}\right],\left[w_{i}^{s-}, w_{i}^{s+}\right]$, and $\left[w_{i}^{g-}, w_{i}^{g+}\right]$, respectively, satisfy $\sum_{i=1}^{L} w_{i}^{d}=1, \quad \sum_{i=1}^{L} w_{i}^{s}=1$, and $\sum_{i=1}^{L} w_{i}^{g}=1$. The integrated weights of attributes $\bar{w}_{i}(i=1, \ldots, L)$ are then used to generate solutions to MADA problems.

\subsection{Generation of solution}

Individual assessments of alternatives on each attribute weighted by the integrated weights $\bar{w}_{i}$ can be combined using the ER analytical algorithm (Wang et al. 2006a) to generate the overall assessments of alternatives, which can be further combined with utilities of grades to determine the minimum and maximum expected utilities of alternatives. As mentioned in Section 3.1, $\bar{w}_{i}$ is associated three coefficients $\theta_{d}, \theta_{s}$, and $\theta_{g}$ such that $0 \leq \theta_{d} \leq 1,0 \leq \theta_{s} \leq 1,0$ $\leq \theta_{g} \leq 1$, and $\theta_{d}+\theta_{s}+\theta_{g}=1$, and three sets of weights $w_{i}^{d}, w_{i}^{s}$, and $w_{i}^{g}$ such that $w_{i}^{d} \in\left[w_{i}^{d-}, w_{i}^{d+}\right], \quad w_{i}^{s} \in\left[w_{i}^{s-}, w_{i}^{s+}\right], \quad w_{i}^{g} \in\left[w_{i}^{g-}, w_{i}^{g+}\right], \quad \sum_{i=1}^{L} w_{i}^{d}=1, \quad \sum_{i=1}^{L} w_{i}^{s}=1, \quad$ and $\sum_{i=1}^{L} w_{i}^{g}=1$. This means that $\bar{w}_{i}$ is not precise. To take into account all possible $\bar{w}_{i}$, the following optimization model is constructed to determine the minimum and maximum expected utilities of alternative $a_{l}$, denoted by $u^{-}\left(a_{l}\right)$ and $u^{+}\left(a_{l}\right)$ respectively.

$$
\begin{array}{ll}
\text { MIN } & u^{-}\left(a_{l}\right)=\sum_{n=2}^{N} \beta_{n}\left(a_{l}\right) u\left(H_{n}\right)+\left(\beta_{1}\left(a_{l}\right)+\beta_{\Omega}\left(a_{l}\right)\right) u\left(H_{1}\right) \\
\text { s.t. } & \bar{w}_{i}=\theta_{d}^{*} \cdot w_{i}^{d^{*}}+\theta_{s}^{*} \cdot w_{i}^{s^{*}}+\theta_{g}^{*} \cdot w_{i}^{g^{*}}, i=1, \ldots, L, \\
& 0 \leq \theta_{d}^{*} \leq 1, \\
& w_{i}^{d-} \leq w_{i}^{d^{*}} \leq w_{i}^{d+}, i=1, \ldots, L, \\
& \sum_{i=1}^{L} w_{i}^{d^{*}}=1, \\
& 0 \leq \theta_{s}^{*} \leq 1,
\end{array}
$$




$$
\begin{aligned}
& w_{i}^{s-} \leq w_{i}^{s^{*}} \leq w_{i}^{s+}, i=1, \ldots, L, \\
& \sum_{i=1}^{L} w_{i}^{s^{*}}=1, \\
& 0 \leq \theta_{g}^{*} \leq 1, \\
& w_{i}^{g-} \leq w_{i}^{g^{*}} \leq w_{i}^{g+}, i=1, \ldots, L, \\
& \sum_{i=1}^{L} w_{i}^{g^{*}}=1, \\
& \theta_{d}^{*}+\theta_{s}^{*}+\theta_{g}^{*}=1 .
\end{aligned}
$$

In this model, $w_{i}^{d^{*}}, w_{i}^{s^{*}}, w_{i}^{g^{*}}, \theta_{d}^{*}, \theta_{s}^{*}$, and $\theta_{g}^{*}$ represent decision variables. To obtain the values of $\theta_{d}^{*}, \theta_{s}^{*}$, and $\theta_{g}^{*}$ by using the optimization model relieves the burden on a decision maker to provide those values which are the coefficients of $w_{i}^{d^{*}}, w_{i}^{s^{*}}$, and $w_{i}^{g^{* *}}$ when generating the integrated weight of attribute $e_{i}$. The overall assessment $B\left(y\left(a_{l}\right)\right)$ is generated by using the ER analytical algorithm (Wang et al. 2006a) from individual assessments of alternative $a_{l}$ on each attribute together with $\bar{w}_{i}$. Solving this optimization model will generate the minimum $u^{-}\left(a_{l}\right)$. When the objective of this optimization model is changed to "MAX $u^{+}\left(a_{l}\right)=\sum_{n=1}^{N-1} \beta_{n}\left(a_{l}\right) u\left(H_{n}\right)+\left(\beta_{N}\left(a_{l}\right)+\beta_{\Omega}\left(a_{l}\right)\right) u\left(H_{N}\right)$ ", the maximum $u^{+}\left(a_{l}\right)$ will be obtained. From the optimal $\left[u^{-}\left(a_{l}\right), u^{+}\left(a_{l}\right)\right](l=1, \ldots, M)$, comparison between alternatives can be made for further analysis or the generation of solutions to the MADA problem with the assistance of decision rules consistent with the preferences or behaviors of the decision maker.

When the optimal $\left[u^{-}\left(a_{l}\right), u^{+}\left(a_{l}\right)\right]$ is obtained, the maximax and maximin decision rules can be used to compare alternatives by their expected utilities. Alternatives are compared by their maximum expected utilities when the maximax decision rule is adopted while alternatives are compared by their minimum expected utilities when the maximin decision rule is adopted. That is, alternatives are compared in their best and worst situations when the maximax and maximin decision rules are applied. On the other hand, the weighted combination of the maximax and maximin decision rules with the optimism degree $\gamma$ limited to [0,1] forms Hurwicz rule, which means that the two rules are special cases of Hurwicz rule and a compromised situation is usually considered in Hurwicz rule. To cover all possible situations, Hurwicz rule is adopted to make selection, in which $\gamma \cdot u^{+}\left(a_{l}\right)+(1-\gamma) \cdot u^{-}\left(a_{l}\right)$ is used to compare alternatives. Given two alternatives $a_{l}$ and $a_{m}$, alternative $a_{l}$ is superior to $a_{m}$ when $u^{+}\left(a_{l}\right)>$ 
$u^{+}\left(a_{m}\right)$ and $u^{-}\left(a_{l}\right)>u^{-}\left(a_{m}\right)$ while $a_{l}$ is inferior to $a_{m}$ when $u^{+}\left(a_{l}\right)<u^{+}\left(a_{m}\right)$ and $u^{-}\left(a_{l}\right)<u^{-}\left(a_{m}\right)$. The two conclusions are independent of the value of $\gamma$. In other two situations where $u^{+}\left(a_{l}\right)>$ $u^{+}\left(a_{m}\right)$ and $u^{-}\left(a_{l}\right)<u^{-}\left(a_{m}\right)$, or $u^{+}\left(a_{l}\right)<u^{+}\left(a_{m}\right)$ and $u^{-}\left(a_{l}\right)>u^{-}\left(a_{m}\right)$, making a comparison between alternatives $a_{l}$ and $a_{m}$ is dependent of the value of $\gamma$, which is analyzed below.

Theorem 4. Given the optimal $\left[u^{-}\left(a_{l}\right), u^{+}\left(a_{l}\right)\right]$ and $\left[u^{-}\left(a_{m}\right), u^{+}\left(a_{m}\right)\right]$ for two alternatives $a_{l}$ and $a_{m}$, suppose that $E\left(a_{l}\right)=\gamma \cdot u^{+}\left(a_{l}\right)+(1-\gamma) \cdot u^{-}\left(a_{l}\right)$ and $E\left(a_{m}\right)=\gamma \cdot u^{+}\left(a_{m}\right)+(1-\gamma) \cdot u^{-}\left(a_{m}\right)$ represent the expected utilities of alternatives $a_{l}$ and $a_{m}$ in Hurwicz rule and $\Delta E\left(a_{l m}\right)=E\left(a_{l}\right)-E\left(a_{m}\right)$ represents the difference between the expected utilities of $a_{l}$ and $a_{m}$, then we have the following conclusions.

(1) When $u^{+}\left(a_{l}\right)>u^{+}\left(a_{m}\right)$ and $u^{-}\left(a_{l}\right)<u^{-}\left(a_{m}\right), \Delta E\left(a_{l m}\right)$ is monotonously increasing with respect to $\gamma$, and it is smaller than, equal to, and larger than 0 when $\gamma$ is limited to $\left[0, \gamma^{*}\right),\left[\gamma^{*}\right.$, $\left.\gamma^{*}\right]$, and $\left(\gamma^{*}, 1\right]$, respectively, where

$$
\gamma^{*}=\frac{u^{-}\left(a_{m}\right)-u^{-}\left(a_{l}\right)}{\left(u^{+}\left(a_{l}\right)-u^{-}\left(a_{l}\right)\right)-\left(u^{+}\left(a_{m}\right)-u^{-}\left(a_{m}\right)\right)} .
$$

(2) When $u^{+}\left(a_{l}\right)<u^{+}\left(a_{m}\right)$ and $u^{-}\left(a_{l}\right)>u^{-}\left(a_{m}\right), \Delta E\left(a_{l m}\right)$ is monotonously decreasing with respect to $\gamma$, and it is larger than, equal to, and smaller than 0 when $\gamma$ is limited to $\left[0, \gamma^{*}\right),\left[\gamma^{*}\right.$, $\left.\gamma^{*}\right]$, and $\left(\gamma^{*}, 1\right]$, respectively.

Theorem 4 is proven in Appendix. This theorem indicates that different values of $\gamma$ may result in different comparison outcomes between two alternatives. In general, the value range of the optimism degree $\gamma$, i.e., [0,1] can be simply divided into two intervals $[0,0.5]$ and $[0.5,1]$. To compare two alternatives, a decision maker is inclined to anticipate their best situations when $\gamma$ is limited to $[0.5,1]$ while he or she anticipates their worst situations when $\gamma$ is limited to $[0,0.5]$. Suppose that a decision maker is capable of providing either a precise $\gamma$ or a value range of $\gamma$, i.e., $\left[\gamma^{-}, \gamma^{+}\right]$. In the two situations where $u^{+}\left(a_{l}\right)>u^{+}\left(a_{m}\right)$ and $u^{-}\left(a_{l}\right)<$ $u^{-}\left(a_{m}\right)$, or $u^{+}\left(a_{l}\right)<u^{+}\left(a_{m}\right)$ and $u^{-}\left(a_{l}\right)>u^{-}\left(a_{m}\right)$, a certain comparison outcome can be obtained when $\left[\gamma^{-}, \gamma^{+}\right] \subset\left[0, \gamma^{*}\right)$ or $\left[\gamma^{-}, \gamma^{+}\right] \subset\left(\gamma^{*}, 1\right]$. If $\gamma^{*}$ is in the range $\left[\gamma^{-}, \gamma^{+}\right]$, then there is uncertainty about the outcomes of comparison between alternatives $a_{l}$ and $a_{m}$. Within the intervals $\left[\gamma^{-}, \gamma^{*}\right)$ and $\left(\gamma^{*}, \gamma^{+}\right]$, the rankings between alternatives $a_{l}$ and $a_{m}$ are reversed in the above two situations. As there is no other preference information about $\left[\gamma^{-}, \gamma^{+}\right]$provided by a decision maker, it is assumed that the outcome of comparison between alternatives $a_{l}$ and $a_{m}$ within the interval $\left[\gamma^{-}, \gamma^{*}\right)$ is preferred when $\gamma^{*}-\gamma^{-}>\gamma^{+}-\gamma^{*}$ while the outcome of comparison within the interval $\left(\gamma^{*}, \gamma^{+}\right]$is preferred when $\gamma^{*}-\gamma^{-}<\gamma^{+}-\gamma^{*}$. Such comparison is formally defined below.

Definition 5. Given the optimal $\left[u^{-}\left(a_{l}\right), u^{+}\left(a_{l}\right)\right]$ and $\left[u^{-}\left(a_{m}\right), u^{+}\left(a_{m}\right)\right]$ for two alternatives $a_{l}$ and $a_{m}$, suppose that $\gamma^{*}$ is calculated using Eq. (39) and $\left[\gamma^{-}, \gamma^{+}\right]$is provided by a decision maker, 
then we have

$$
\begin{aligned}
& a_{l} \succ a_{m} \text { if } u^{+}\left(a_{l}\right)>u^{+}\left(a_{m}\right) \text { and } u^{-}\left(a_{l}\right)>u^{-}\left(a_{m}\right) \text {, or } u^{+}\left(a_{l}\right)>u^{+}\left(a_{m}\right) \text { and } u^{-}\left(a_{l}\right)=u^{-}\left(a_{m}\right) \text {, or } \\
& u^{+}\left(a_{l}\right)=u^{+}\left(a_{m}\right) \text { and } u^{-}\left(a_{l}\right)>u^{-}\left(a_{m}\right), \\
& a_{l} \succ a_{m} \text { if }\left[\gamma^{-}, \gamma^{+}\right] \subset\left(\gamma^{*}, 1\right] \text { or } \gamma^{*} \in\left[\gamma^{-}, \gamma^{+}\right] \text {with } \gamma^{*}-\gamma^{-}<\gamma^{+}-\gamma^{*} \\
& \text { when } u^{+}\left(a_{l}\right)>u^{+}\left(a_{m}\right) \text { and } u^{-}\left(a_{l}\right)<u^{-}\left(a_{m}\right), \\
& a_{l} \succ a_{m} \text { if }\left[\gamma^{-}, \gamma^{+}\right] \subset\left[0, \gamma^{*}\right) \text { or } \gamma^{*} \in\left[\gamma^{-}, \gamma^{+}\right] \text {with } \gamma^{*}-\gamma^{-}>\gamma^{+}-\gamma^{*} \\
& \text { when } u^{+}\left(a_{l}\right)<u^{+}\left(a_{m}\right) \text { and } u^{-}\left(a_{l}\right)>u^{-}\left(a_{m}\right) \text {, and } \\
& a_{l}=a_{m} \text { if } u^{+}\left(a_{l}\right)=u^{+}\left(a_{m}\right) \text { and } u^{-}\left(a_{l}\right)=u^{-}\left(a_{m}\right) \text {, or } \gamma^{*} \in\left[\gamma^{-}, \gamma^{+}\right] \text {with } \gamma^{*}-\gamma^{-}=\gamma^{+}-\gamma^{*}
\end{aligned}
$$

where the notation " $\succ$ " denotes "is superior to".

If any of the first three situations in Definition 5 occurs, we can know that alternative $a_{l}$ is superior to $a_{m}$. Otherwise, a converse conclusion can be made. It should be noticed that if a decision maker cannot accept the comparison outcome generated in accordance with Definition 5, he or she can reconsider $\left[\gamma^{-}, \gamma^{+}\right]$. To facilitate the comparison among multiple alternatives by using their expected utilities, transitivity of the comparison outcomes among any three alternatives needs to be analyzed in order to avoid the problem of comparison cycle and guarantee the validity of the outcomes (Yang et al., 2016). That is, given $\left[\gamma^{-}, \gamma^{+}\right]$, if $a_{l} \succ$ $a_{m}$ and $a_{m} \succ a_{k}$ as defined in Definition 5, then there should be that $a_{l} \succ a_{k}$.

Theorem 5. Given the optimal $\left[u^{-}\left(a_{l}\right), u^{+}\left(a_{l}\right)\right],\left[u^{-}\left(a_{m}\right), u^{+}\left(a_{m}\right)\right]$, and $\left[u^{-}\left(a_{k}\right), u^{+}\left(a_{k}\right)\right]$ for three alternatives $a_{l}, a_{m}$, and $a_{k}$, suppose that $a_{l} \succ a_{m}$ and $a_{m} \succ a_{k}$ in accordance with Definition 5 on the condition that $\left[\gamma^{-}, \gamma^{+}\right]$is provided, then we have $a_{l} \succ a_{k}$.

Theorem 5 is proven in Appendix. By using Definition 5, we can construct a binary comparison matrix denoted by

$$
B=\left(b_{l m}\right)_{M \times M},
$$

where $b_{l m}=1(l \neq m)$ stands for $a_{l} \succ a_{m}$ and $b_{l m}=0(l \neq m)$ for $a_{l} \prec a_{m}$ (i.e., $\left.a_{m} \succ a_{l}\right)$. In particular, $b_{l l}$ is set as 0 . Suppose that the superior indicator of alternative $a_{l}$ is defined as $b_{l}=$ $\sum_{m=1}^{M} b_{l m}$, then the ranking of $a_{l}$ is calculated as $M-b_{l}$. Theorem 5 can effectively avoid the problem of comparison cycle to guarantee the rationality and robustness of the ranking of each alternative from $M-b_{l}(l=1, \ldots, M)$. When $a_{l} \succ a_{m}$ and $a_{m} \succ a_{k}$ are judged by following Definition 5 given $\left[\gamma^{-}, \gamma^{+}\right]$, the preference relation between alternatives $a_{l}$ and $a_{m}$ is certain to be $a_{l} \succ a_{k}$ instead of $a_{k} \succ a_{l}$ under the same conditions. The consistency among the preference relations of alternatives is guaranteed. As a result, a valid ranking order of all alternatives can be generated.

\subsection{Process of the proposed method}

The process of finding solutions to MADA problems by using the proposed method can be summarized as follows and shown in Fig. 1. 


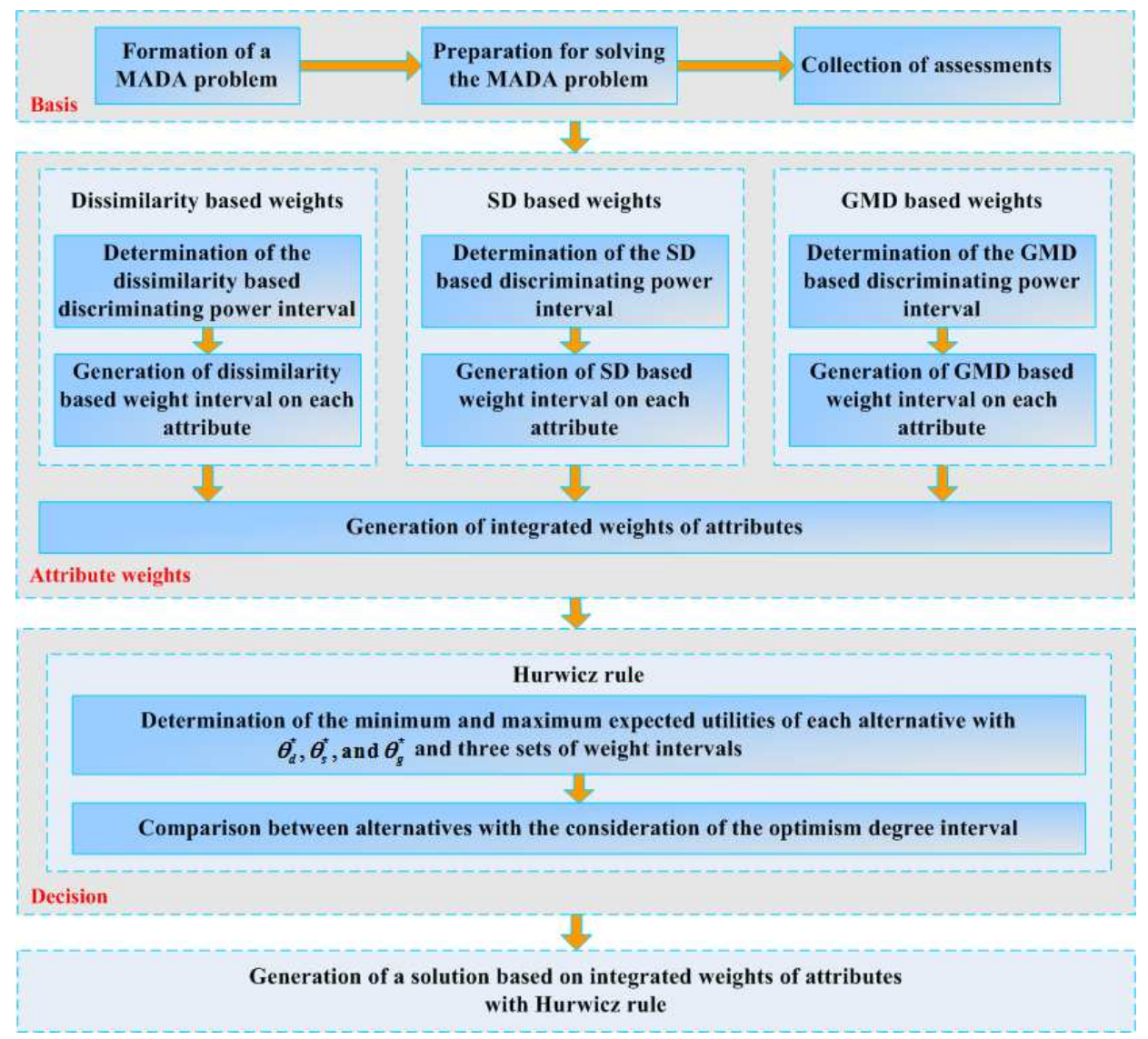

Fig. 1. Process of the proposed method.

Step 1: Form a MADA problem.

A decision maker identifies $L$ attributes and $N$ assessment grades, and lists $M$ alternatives to form a MADA problem.

Step 2: Prepare for the proposed method to solve the MADA problem.

The decision maker specifies $u\left(H_{n}\right)(n=1, \ldots, N)$ and $\left[\gamma^{-}, \gamma^{+}\right]$in Hurwicz rule.

Step 3: Collect assessments from the decision maker.

The decision maker evaluates each alternative on each attribute to provide individual assessments $B\left(e_{i}\left(a_{l}\right)\right)(i=1, \ldots, L, l=1, \ldots, M)$.

Step 4: Determine the integrated weights of attributes.

With the consideration of a general case where there is at least one incomplete individual assessment on an attribute, three pairs of optimization problems in Eqs. (9)-(11), (12)-(14), and (15)-(17), respectively, are solved to generate the dissimilarity based discriminating power interval $\left[\bar{D}^{-}\left(e_{i}\right), \bar{D}^{+}\left(e_{i}\right)\right]$, the $\mathrm{SD}$ based discriminating power interval $\left[\bar{S}^{-}\left(e_{i}\right), \bar{S}^{+}\left(e_{i}\right)\right]$, and the GMD based discriminating power interval $\left[\bar{G}^{-}\left(e_{i}\right), \bar{G}^{+}\left(e_{i}\right)\right]$. From 
the three intervals, the dissimilarity based weight interval $\left[w_{i}^{d-}, w_{i}^{d+}\right]$, the standard deviation based weight interval $\left[w_{i}^{s-}, w_{i}^{s+}\right]$, and the GMD based weight interval $\left[w_{i}^{g-}, w_{i}^{g+}\right]$ are calculated using Eqs. (20)-(21), (22)-(23), and (24)-(25), respectively. Three sets of weights limited to $\left[w_{i}^{d-}, w_{i}^{d+}\right],\left[w_{i}^{s-}, w_{i}^{s+}\right]$, and $\left[w_{i}^{g-}, w_{i}^{g+}\right]$ are then combined by the non-negative coefficients $\theta_{d}, \theta_{s}$, and $\theta_{g}$ such that $\theta_{d}+\theta_{s}+\theta_{g}=1$ to generate the integrated weights of attributes.

Step 5: Determine the minimum and maximum expected utilities of each alternative.

On the condition that the three coefficients $\theta_{d}, \theta_{s}$, and $\theta_{g}$ are relaxed as variables satisfying $0 \leq \theta_{d} \leq 1,0 \leq \theta_{s} \leq 1,0 \leq \theta_{g} \leq 1$, and $\theta_{d}+\theta_{s}+\theta_{g}=1$, the optimization model in Eqs. (27)-(38) is solved to generate the optimal $u^{-}\left(a_{l}\right)$. When the objective of this optimization model is changed to "MAX $u^{+}\left(a_{l}\right)=\sum_{n=1}^{N-1} \beta_{n}\left(a_{l}\right) u\left(H_{n}\right)+\left(\beta_{N}\left(a_{l}\right)+\beta_{\Omega}\left(a_{l}\right)\right) u\left(H_{N}\right)$ ", the optimal $u^{+}\left(a_{l}\right)$ is obtained.

Step 6: Compare alternatives using Hurwicz rule.

Alternatives $a_{l}$ and $a_{m}(m=l+1, \ldots, M)$ are compared by using Definition 5 to determine the upper triangle of the binary comparison matrix $B$ as defined in Eq. (44). Then the lower triangle of $B$ can be directly determined from the upper triangle in accordance with $b_{l m}+b_{m l}=$ 1.

Step 7: Generate a ranking order of all alternatives.

From the binary comparison matrix $B, b_{l}(l=1, \ldots, M)$ is calculated to determine the ranking of alternative $a_{l}$, i.e., $M-b_{l}$. A ranking order of all alternatives is then generated.

Step 8: Finish the process.

The ranking order of all alternatives is considered as a solution to the MADM problem.

\section{Illustrative example}

In this section, a focal firm selection (FFS) problem is analyzed by the proposed method to demonstrate the generation of integrated weights of attributes and the process of finding solutions to MADA problems. The purpose is to choose the most appropriate two focal firms from five candidates to provide lamp accessories for an enterprise located in Tongling of Anhui province of China. A solution system developed in the Matlab environment is employed to analyze the FFS problem.

\subsection{Description of the FFS problem}

Most enterprises, especially small and medium enterprises usually supply products or components to downstream firms which are also called focal firms if they directly provide customers with final goods. In general, an enterprise may supply products or components to 
multiple focal firms. When the requirements, such as order quantity and quality of products or components, of focal firms change, however, the enterprise may be incapable of meeting the requirements of all focal firms simultaneously due to cash flow difficulties or production capacity. In this situation, the enterprise faces the challenge to select one or several appropriate focal firms to provide products or components.

In this paper, we investigate the selection of focal firms for an enterprise located in Tongling of Anhui province of China who primarily provides lamp accessories for many focal firms in the lighting industry. As a small and medium enterprise, its cash flow and production capacity are limited so that it cannot cope with the increase in order quantity and quality of accessories for focal firms. To achieve sustainable development in line with its cash flow and production capacity, the enterprise has to select appropriate focal firms to provide lamp accessories. To address the selection problem, the board of directors firstly identifies five candidates from all focal firms for which the enterprise has provided lamp accessories before. The five candidates include Yankon, Nvc, Opple, Topstar, and Philips. The board of directors wishes to select the most appropriate two focal firms from the five candidates to provide lamp accessories. Note that the board of directors does not want to find the best portfolio of any two focal firms but to find the best focal firm and the second best focal firm. The general manager of the enterprise acts as the decision maker to be responsible for the selection of appropriate focal firms with the help of five experts from the departments of sales, research and development, production, quality management, and finance. Eight attributes are selected to carry out the selection of focal firms, including profits of supply, requirements of supply, scale of supply, scale of focal firm, customer segments of focal firm, market share of focal firm, growth of focal firm, and cooperativeness of focal firm.

Suppose that the five focal firms are represented by $F_{l}(l=1, \ldots, 5)$, and the eight attributes by $e_{i}(i=1, \ldots, 8)$. The five focal firms are assessed on each attribute using the following set of assessment grades: Poor (P), Average (A), Good (G), VeryGood (V), and Excellent (E), i.e., $\Omega=\left\{H_{n}, n=1, \ldots, 5\right\}=\{$ Poor, Average, Good, VeryGood, Excellent $\}=\{P, A, G, V, E\}$. Step 1 is completed.

The decision maker uses a probability assignment approach (Winston 2011) to set the utility of each assessment grade $u\left(H_{n}\right)(n=1, \ldots, 5)$ to be $(0,0.25,0.5,0.75,1)$. The optimism degree interval $\left[\gamma^{-}, \gamma^{+}\right]$is set as $[0,0.5]$ because the decision maker prefers to examine the outcomes from comparing different focal firms in their worst scenarios to avoid potential risks. The decision maker is risk averse as his enterprise has limited cash flow and production capacity which does not allow him to take too much risk. As selecting focal firms is very important for the enterprise, the decision maker is not willing to give subjective judgements to 
assign attribute weights in order to avoid personal biases of his judgments towards those focal firms. To objectively carry out the overall evaluation of the five focal firms, the proposed method is used to determine the integrated weights of attributes and generate the corresponding solution. Step 2 is completed.

\subsection{Generation of solution to the FFS problem}

The decision maker gives his assessments of each of the five focal firms on each of the eight attributes with the assistance of the five experts, as presented in Table 1. For example, the assessment $\{(G, 0.2),(V, 0.6),(\Omega, 0.2)\}$ records that the performance of $F_{1}$ on attribute $e_{1}$ is assessed as 'Good' by one expert, as 'Very Good' by the other three experts, and as 'unclear' by the remaining expert. Step 3 is completed.

\section{Table 1}

Assessment data from the decision maker for the five focal firms.

\begin{tabular}{|c|c|c|c|c|c|}
\hline Attributes & $F_{1}$ & $F_{2}$ & $F_{3}$ & $F_{4}$ & $F_{5}$ \\
\hline$e_{1}$ & $\begin{array}{l}\{(G, 0.2), \\
(V, 0.6), \\
(\Omega, 0.2)\}\end{array}$ & $\begin{array}{l}\{(V, 0.8) \\
(\Omega, 0.2)\}\end{array}$ & $\begin{array}{l}\{(G, 0.2), \\
(V, 0.6), \\
(\Omega, 0.2)\}\end{array}$ & $\begin{array}{l}\{(V, 0.8) \\
(\Omega, 0.2)\}\end{array}$ & $\begin{array}{l}\{(G, 0.4), \\
(V, 0.4), \\
(\Omega, 0.2)\}\end{array}$ \\
\hline$e_{2}$ & $\begin{array}{l}\{(A, 0.2), \\
(G, 0.6) \\
(V, 0.2)\}\end{array}$ & $\begin{array}{l}\{(A, 0.6) \\
(G, 0.4)\}\end{array}$ & $\begin{array}{l}\{(A, 0.2), \\
(G, 0.4) \\
(V, 0.4)\}\end{array}$ & $\begin{array}{l}\{(A, 0.8) \\
(G, 0.2)\}\end{array}$ & $\begin{array}{l}\{(A, 0.8), \\
(G, 0.2)\}\end{array}$ \\
\hline$e_{3}$ & $\begin{array}{l}\{(V, 0.6) \\
(E, 0.4)\}\end{array}$ & $\begin{array}{l}\{(V, 0.8) \\
(E, 0.2)\}\end{array}$ & $\begin{array}{l}\{(G, 0.4), \\
(V, 0.6)\}\end{array}$ & $\begin{array}{l}\{(G, 0.6), \\
(V, 0.4)\}\end{array}$ & $\begin{array}{l}\{(V, 0.2), \\
(E, 0.8)\}\end{array}$ \\
\hline$e_{4}$ & $\begin{array}{l}\{(V, 0.6) \\
(E, 0.2) \\
(\Omega, 0.2)\}\end{array}$ & $\begin{array}{l}\{(V, 0.4) \\
(E, 0.4) \\
(\Omega, 0.2)\}\end{array}$ & $\begin{array}{l}\{(V, 0.4) \\
(E, 0.4) \\
(\Omega, 0.2)\}\end{array}$ & $\begin{array}{l}\{(V, 0.8) \\
(\Omega, 0.2)\}\end{array}$ & $\begin{array}{l}\{(V, 0.2), \\
(E, 0.6), \\
(\Omega, 0.2)\}\end{array}$ \\
\hline$e_{5}$ & $\begin{array}{l}\{(G, 0.4), \\
(V, 0.4), \\
(\Omega, 0.2)\}\end{array}$ & $\begin{array}{l}\{(V, 0.6) \\
(E, 0.2) \\
(\Omega, 0.2)\}\end{array}$ & $\begin{array}{l}\{(G, 0.2), \\
(V, 0.6), \\
(\Omega, 0.2)\}\end{array}$ & $\begin{array}{l}\{(V, 0.2) \\
(E, 0.6) \\
(\Omega, 0.2)\}\end{array}$ & $\begin{array}{l}\{(G, 0.2), \\
(V, 0.6), \\
(\Omega, 0.2)\}\end{array}$ \\
\hline$e_{6}$ & $\begin{array}{l}\{(V, 0.4), \\
(E, 0.2), \\
(\Omega, 0.4)\}\end{array}$ & $\begin{array}{l}\{(V, 0.4), \\
(E, 0.2), \\
(\Omega, 0.4)\}\end{array}$ & $\begin{array}{l}\{(V, 0.2), \\
(E, 0.4), \\
(\Omega, 0.4)\}\end{array}$ & $\begin{array}{l}\{(G, 0.2), \\
(V, 0.4), \\
(\Omega, 0.4)\}\end{array}$ & $\begin{array}{l}\{(V, 0.6), \\
(\Omega, 0.4)\}\end{array}$ \\
\hline$e_{7}$ & $\begin{array}{l}\{(V, 0.6) \\
(E, 0.2) \\
(\Omega, 0.2)\}\end{array}$ & $\begin{array}{l}\{(V, 0.4) \\
(E, 0.4) \\
(\Omega, 0.2)\}\end{array}$ & $\begin{array}{l}\{(G, 0.2), \\
(V, 0.6), \\
(\Omega, 0.2)\}\end{array}$ & $\begin{array}{l}\{(V, 0.6) \\
(E, 0.2) \\
(\Omega, 0.2)\}\end{array}$ & $\begin{array}{l}\{(G, 0.2), \\
(V, 0.6), \\
(\Omega, 0.2)\}\end{array}$ \\
\hline$e_{8}$ & $\begin{array}{l}\{(G, 0.2), \\
(V, 0.6),\end{array}$ & $\begin{array}{l}\{(G, 0.6), \\
(V, 0.2),\end{array}$ & $\begin{array}{l}\{(A, 0.4), \\
(G, 0.4)\end{array}$ & $\begin{array}{l}\{(A, 0.4), \\
(G, 0.4)\end{array}$ & $\begin{array}{l}\{(G, 0.2), \\
(V, 0.6),\end{array}$ \\
\hline
\end{tabular}


By finding the solutions to three pairs of optimization problems in Eqs. (9)-(11), (12)-(14), and (15)-(17) with the data in Table 1, the dissimilarity based discriminating power interval, the SD based discriminating power interval, and the GMD based discriminating power interval on the eight attributes, i.e., $\left[\bar{D}^{-}\left(e_{i}\right), \bar{D}^{+}\left(e_{i}\right)\right],\left[\bar{S}^{-}\left(e_{i}\right), \bar{S}^{+}\left(e_{i}\right)\right]$, and $\left[\bar{G}^{-}\left(e_{i}\right), \bar{G}^{+}\left(e_{i}\right)\right]$ are obtained and presented in Table 2. Such intervals are then used to calculate three sets of weight intervals, i.e., $\left[w_{i}^{d-}, w_{i}^{d+}\right],\left[w_{i}^{s-}, w_{i}^{s+}\right]$, and $\left[w_{i}^{g-}, w_{i}^{g+}\right]$ in accordance with Eqs. (20)-(21), (22)-(23), and (24)-(25), which are presented in Table 3. Step 4 is completed.

\section{Table 2}

Three types of discriminating power intervals on the eight attributes.

\begin{tabular}{clll}
\hline Attributes & \multicolumn{1}{c}{$\left[\bar{D}^{-}\left(e_{i}\right), \bar{D}^{+}\left(e_{i}\right)\right]$} & \multicolumn{1}{c}{$\left[\bar{S}^{-}\left(e_{i}\right), \bar{S}^{+}\left(e_{i}\right)\right]$} & \multicolumn{1}{c}{$\left[\bar{G}^{-}\left(e_{i}\right), \bar{G}^{+}\left(e_{i}\right)\right]$} \\
\hline$e_{1}$ & {$[0.0034,0.108]$} & {$[0.0017,0.0785]$} & {$[0.0016,0.0968]$} \\
$e_{2}$ & {$[0.08,0.08]$} & {$[0.0473,0.0473]$} & {$[0.064,0.064]$} \\
$e_{3}$ & {$[0.12,0.12]$} & {$[0.0825,0.0825]$} & {$[0.1144,0.1144]$} \\
$e_{4}$ & {$[0.01,0.17]$} & {$[0.005,0.1236]$} & {$[0.0064,0.1552]$} \\
$e_{5}$ & {$[0.022,0.2153]$} & {$[0.0197,0.1743]$} & {$[0.0184,0.198]$} \\
$e_{6}$ & {$[0.0019,0.2622]$} & {$[0.0013,0.3041]$} & {$[0.0016,0.2912]$} \\
$e_{7}$ & {$[0.004,0.1242]$} & {$[0.002,0.105]$} & {$[0.0016,0.1164]$} \\
$e_{8}$ & {$[0.038,0.2579]$} & {$[0.0257,0.175]$} & {$[0.0324,0.2152]$} \\
\hline
\end{tabular}

\section{Table 3}

Three types of weight intervals of attributes in line with the corresponding discriminating power intervals.

\begin{tabular}{crrr}
\hline Attributes & {$\left[w_{i}^{d-}, w_{i}^{d+}\right]$} & {$\left[w_{i}^{s-}, w_{i}^{s+}\right]$} & {$\left[w_{i}^{g-}, w_{i}^{g+}\right]$} \\
\hline$e_{1}$ & {$[0.0028,0.2813]$} & {$[0.0016,0.2996]$} & {$[0.0014,0.2884]$} \\
$e_{2}$ & {$[0.0598,0.2863]$} & {$[0.0434,0.2553]$} & {$[0.0512,0.2662]$} \\
$e_{3}$ & {$[0.0897,0.4295]$} & {$[0.0757,0.4455]$} & {$[0.0914,0.4758]$} \\
$e_{4}$ & {$[0.0085,0.3869]$} & {$[0.0051,0.4068]$} & {$[0.0058,0.3987]$} \\
$e_{5}$ & {$[0.0192,0.4555]$} & {$[0.0211,0.5129]$} & {$[0.0172,0.4714]$} \\
$e_{6}$ & {$[0.0018,0.4858]$} & {$[0.0016,0.623]$} & {$[0.0017,0.5494]$} \\
$e_{7}$ & {$[0.0033,0.3109]$} & {$[0.002,0.3644]$} & {$[0.0014,0.3277]$} \\
$e_{8}$ & {$[0.034,0.5165]$} & {$[0.0274,0.5231]$} & {$[0.0303,0.5085]$} \\
\hline
\end{tabular}


On the condition that the three coefficients $\theta_{d}, \theta_{s}$, and $\theta_{g}$ are relaxed as variables satisfying $0 \leq \theta_{d} \leq 1,0 \leq \theta_{s} \leq 1,0 \leq \theta_{g} \leq 1$, and $\theta_{d}+\theta_{s}+\theta_{g}=1$, from finding the solutions to the optimization model in Eqs. (27)-(38) with the objectives of "MIN $u^{-}\left(F_{l}\right)$ " and "MAX $u^{+}\left(F_{l}\right)$ ") the optimal $\left[u^{-}\left(F_{l}\right), u^{+}\left(F_{l}\right)\right](l=1, \ldots, 5)$ is obtained as ([0.5362, 0.8619], [0.4635, 0.8648], [0.4098, 0.8946], [0.3366, 0.868], [0.455, 0.9278]). Step 5 is completed.

To use Definition 5 to compare focal firms, the critical value of the optimism degree in Hurwicz rule, i.e., $\gamma^{*}$ between any two focal firms is calculated in accordance with Eq. (39), as presented in Table 4 . Note that because $u^{-}\left(F_{3}\right)>u^{-}\left(F_{4}\right)$ and $u^{+}\left(F_{3}\right)>u^{+}\left(F_{4}\right), u^{-}\left(F_{3}\right)<u^{-}\left(F_{5}\right)$ and $u^{+}\left(F_{3}\right)<u^{+}\left(F_{5}\right)$, and $u^{-}\left(F_{4}\right)<u^{-}\left(F_{5}\right)$ and $u^{+}\left(F_{4}\right)<u^{+}\left(F_{5}\right)$, there are no critical values for those cases and the notation "-" is placed in the corresponding cells in the table. Then from Definition 5 the comparison outcomes between any two focal firms are generated and also presented in Table 4. Such outcomes are further used to generate the binary comparison matrix $B$, as presented in Table 5. Step 6 is completed.

\section{Table 4}

Critical value of the optimism degree in Hurwicz rule between any two focal firms and the comparison outcomes (in brackets) between the two focal firms.

\begin{tabular}{|c|c|c|c|c|c|}
\hline & $F_{1}$ & $F_{2}$ & $F_{3}$ & $F_{4}$ & $F_{5}$ \\
\hline$F_{1}$ & & $0.9616(\succ)$ & $0.7945(\succ)$ & $0.9703(\succ)$ & $0.552(\succ)$ \\
\hline$F_{2}$ & & & $0.6431(\succ)$ & $0.9754(\succ)$ & $0.1189(\prec)$ \\
\hline$F_{3}$ & & & & $-(\succ)$ & $-(\prec)$ \\
\hline$F_{4}$ & & & & & $-(\prec)$ \\
\hline$F_{5}$ & & & & & \\
\hline
\end{tabular}

\section{Table 5}

Binary comparison matrix.

\begin{tabular}{lccccc}
\hline & $F_{1}$ & $F_{2}$ & $F_{3}$ & $F_{4}$ & $F_{5}$ \\
\hline$F_{1}$ & 0 & 1 & 1 & 1 & 1 \\
$F_{2}$ & 0 & 0 & 1 & 1 & 0 \\
$F_{3}$ & 0 & 0 & 0 & 1 & 0 \\
$F_{4}$ & 0 & 0 & 0 & 0 & 0 \\
$F_{5}$ & 0 & 1 & 1 & 1 & 0 \\
\hline
\end{tabular}

It is clear from the binary comparison matrix that $b_{l}(l=1, \ldots, 5)=(4,2,1,0,3)$, which results in the rankings of the five focal firms, i.e., $(1,3,4,5,2)$ for $F_{1}$ to $F_{5}$ respectively. As a 
result, a ranking order of the five focal firms is obtained as $F_{1} \succ F_{5} \succ F_{2} \succ F_{3} \succ F_{4}$. It should be noticed that such a ranking order can be directly obtained from the comparison outcomes between any two focal firms in Table 4 because there are limited alternatives in the FFS problem. For the real problems with a large number of alternatives, the binary comparison matrix will be necessary for generating a ranking order. Step 7 is completed.

The ranking order of the five focal firms indicates that Yankon $\left(F_{1}\right)$ and Philips $\left(F_{5}\right)$ should be selected with the preferential order of $F_{1} \succ F_{5}$ to provide lamp accessories. This is the solution to the FFS problem. Step 8 is completed.

Next, we will find the solutions to the FFS problem on the assumption that different optimism degree intervals are provided to compare them with the above solution. This helps highlight the significant influence of optimism degree interval on solutions obtained by using the proposed method.

\subsection{Influence of optimism degree interval on solutions}

In the above solution process, the optimism degree interval $\left[\gamma^{-}, \gamma^{+}\right]$is set as $[0,0.5]$ by the decision maker due to the limited cash flow and production capacity of the enterprise. Assume that different optimism degree intervals are set, we present what will happen to the solutions to the FFS problem below.

After the optimal $\left[u^{-}\left(F_{l}\right), u^{+}\left(F_{l}\right)\right](l=1, \ldots, 5)$ is obtained, different optimism degree intervals may generate different comparison outcomes between alternatives when Hurwicz rule is applied. To demonstrate this, without loss of generality, $\left[\gamma^{-}, \gamma^{+}\right]$is set as $[0,0.2],[0.1$, $0.3],[0.3,0.5],[0.5,0.7],[0.6,0.8],[0.8,1]$, and [0.5, 1], respectively. For each setting, the comparison outcomes between any two focal firms are recalculated using Definition 5 and presented in Table 6. Also, the corresponding binary comparison matrices are reobtained and presented in Table 7, where " $(0,0,0,0,0,0,0)$ " and " $(1,1,1,1,1,1,1)$ " mean that such comparison outcomes are independent of $\left[\gamma^{-}, \gamma^{+}\right]$.

\section{Table 6}

Comparison outcomes between any two focal firms with different optimism degree intervals.

\begin{tabular}{|c|c|c|c|c|}
\hline$F_{1}$ & $F_{2}$ & $F_{3}$ & $F_{4}$ & $F_{5}$ \\
\hline$F_{1}$ & $\begin{array}{l}(\succ, \succ, \succ, \\
\succ, \succ, \quad \succ, \\
\succ)\end{array}$ & $\begin{array}{l}\left(\begin{array}{ll}\succ, & \succ, \\
\succ, & \succ,\end{array}\right. \\
\succ)\end{array}$ & $\begin{array}{l}(\succ, \succ, \succ, \\
\succ, \succ, \quad \succ, \\
\succ)\end{array}$ & $\begin{array}{ll}(\succ, & \succ, \quad \succ, \\
\prec, & \prec, \quad \prec, \\
\prec) & \end{array}$ \\
\hline$F_{2}$ & & $\begin{array}{l}\left(\begin{array}{ll}\succ, & \succ, \\
\succ, & \prec,\end{array}\right. \\
\prec)\end{array}$ & $\begin{array}{l}(\succ, \succ, \quad \succ, \\
\succ, \succ, \quad \succ, \\
\succ)\end{array}$ & 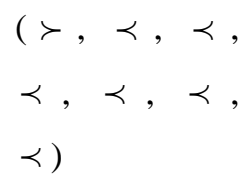 \\
\hline$F_{3}$ & & & $(\succ, \succ, \succ$, & $(\prec, \prec, \prec$, \\
\hline
\end{tabular}




$\begin{aligned} \succ, \succ, \succ, & \prec, \prec, \prec, \\ \succ) & \prec) \\ & (\prec, \prec, \prec, \\ & \prec, \prec, \prec, \\ & \prec)\end{aligned}$

\section{Table 7}

Binary comparison matrix with different optimism degree intervals.

\begin{tabular}{|c|c|c|c|c|c|}
\hline & $F_{1}$ & $F_{2}$ & $F_{3}$ & $F_{4}$ & $F_{5}$ \\
\hline$F_{1}$ & $\begin{array}{l}(0,0,0,0,0,0, \\
0)\end{array}$ & $\begin{array}{l}(1,1,1,1,1,1 \text {, } \\
1)\end{array}$ & $\begin{array}{l}(1,1,1,1,1,0 \text {, } \\
1)\end{array}$ & $\begin{array}{l}(1,1,1,1,1,1 \text {, } \\
1)\end{array}$ & $\begin{array}{l}(1,1,1,0,0,0, \\
0)\end{array}$ \\
\hline$F_{2}$ & $\begin{array}{l}(0,0,0,0,0,0, \\
0)\end{array}$ & $\begin{array}{l}(0,0,0,0,0,0, \\
0)\end{array}$ & $\begin{array}{l}(1,1,1,1,0,0, \\
0)\end{array}$ & $\begin{array}{l}(1,1,1,1,1,1 \text {, } \\
1)\end{array}$ & $\begin{array}{l}(1,0,0,0,0,0, \\
0)\end{array}$ \\
\hline$F_{3}$ & $\begin{array}{l}(0,0,0,0,0,1, \\
0)\end{array}$ & $\begin{array}{l}(0,0,0,0,1,1 \text {, } \\
1)\end{array}$ & $\begin{array}{l}(0,0,0,0,0,0, \\
0)\end{array}$ & $\begin{array}{l}(1,1,1,1,1,1 \text {, } \\
1)\end{array}$ & $\begin{array}{l}(0,0,0,0,0,0, \\
0)\end{array}$ \\
\hline$F_{4}$ & $\begin{array}{l}(0,0,0,0,0,0, \\
0)\end{array}$ & $\begin{array}{l}(0,0,0,0,0,0, \\
0)\end{array}$ & $\begin{array}{l}(0,0,0,0,0,0, \\
0)\end{array}$ & $\begin{array}{l}(0,0,0,0,0,0, \\
0)\end{array}$ & $\begin{array}{l}(0,0,0,0,0,0, \\
0)\end{array}$ \\
\hline$F_{5}$ & $\begin{array}{l}(0,0,0,1,1,1, \\
1)\end{array}$ & $\begin{array}{l}(0,1,1,1,1,1 \text {, } \\
1)\end{array}$ & $\begin{array}{l}(1,1,1,1,1,1 \text {, } \\
1)\end{array}$ & $\begin{array}{l}(1,1,1,1,1,1 \text {, } \\
1)\end{array}$ & $\begin{array}{l}(0,0,0,0,0,0, \\
0)\end{array}$ \\
\hline
\end{tabular}

Tables 6 and 7 indicate that different optimism degree intervals can result in different comparison outcomes in most situations, such as the comparison outcomes between $F_{1}$ and $F_{3}$, $F_{1}$ and $F_{5}, F_{2}$ and $F_{3}$, and $F_{2}$ and $F_{5}$. In particular, the comparison outcomes between $F_{1}$ and $F_{5}$ and $F_{2}$ and $F_{3}$ have significantly changed with the increase in $\left[\gamma^{-}, \gamma^{+}\right]$. From the binary comparison matrices with different optimism degree intervals in Table $7, b_{l}(l=1, \ldots, 5)$ and the ranking of each focal firm are obtained and presented in Table 8 , where the element " $4 ; 1$ " associated with $F_{1}$ and $\left[\gamma^{-}, \gamma^{+}\right]=[0,0.2]$ means that $b_{1}=4$ and the ranking of $F_{1}$ is 1 . Table 8 shows that the rankings of $F_{1}, F_{2}, F_{3}$, and $F_{5}$ have significantly changed with the increase in $\left[\gamma^{-}, \gamma^{+}\right]$. In particular, when $\left[\gamma^{-}, \gamma^{+}\right]$is set as $[0,0.2],[0.5,0.7],[0.6,0.8],[0.8,1]$, and $[0.5,1]$, the solutions to the FFS problem are $F_{1}$ and $F_{2}$ with the preferential order of $F_{1} \succ F_{2}, F_{5}$ and $F_{1}$ with the preferential order of $F_{5} \succ F_{1}, F_{5}$ and $F_{1}$ with the preferential order of $F_{5} \succ F_{1}, F_{5}$ and $F_{3}$ with the preferential order of $F_{5} \succ F_{3}$, and $F_{5}$ and $F_{1}$ with the preferential order of $F_{5}$ $\succ F_{1}$, which are clearly different from the solution generated in Section 4.2. All these verify the great influence of $\left[\gamma^{-}, \gamma^{+}\right]$on solutions to the FFS problem. 
Table 8

Superior indicator and ranking of each focal firm with different optimism degree intervals.

\begin{tabular}{clllllll}
\hline$\left[\gamma^{-}, \gamma^{+}\right]$ & {$[0,0.2]$} & {$[0.1,0.3]$} & {$[0.3,0.5]$} & {$[0.5,0.7]$} & {$[0.6,0.8]$} & {$[0.8,1]$} & {$[0.5,1]$} \\
\hline$F_{1}$ & $4 ; 1$ & $4 ; 1$ & $4 ; 1$ & $3 ; 2$ & $3 ; 2$ & $2 ; 3$ & $3 ; 2$ \\
$F_{2}$ & $3 ; 2$ & $2 ; 3$ & $2 ; 3$ & $2 ; 3$ & $1 ; 4$ & $1 ; 4$ & $1 ; 4$ \\
$F_{3}$ & $1 ; 4$ & $1 ; 4$ & $1 ; 4$ & $1 ; 4$ & $2 ; 3$ & $3 ; 2$ & $2 ; 3$ \\
$F_{4}$ & $0 ; 5$ & $0 ; 5$ & $0 ; 5$ & $0 ; 5$ & $0 ; 5$ & $0 ; 5$ & $0 ; 5$ \\
$F_{5}$ & $2 ; 3$ & $3 ; 2$ & $3 ; 2$ & $4 ; 1$ & $4 ; 1$ & $4 ; 1$ & $4 ; 1$ \\
\hline
\end{tabular}

\section{Conclusions}

Attribute weight assignment is an important step in MADA. When there are no subjective judgments available for attribute weight assignment, one way of determining the weights is to use the information or discriminating power contained in performances of alternatives on each attribute. As presented in Section 2, it is difficult to measure the discriminating power among the performances represented by belief distributions. The strategy of using discriminating power among scalars transformed from belief distributions is infeasible because the transformed scalars cannot reflect the diversity in performances represented by belief distributions over a set of grades which have different utility values. To address this challenge, we have defined three types of discriminating power contained in the distributed assessments of alternatives on different attributes, which are the dissimilarity based discriminating power, the SD based discriminating power, and the GMD based discriminating power. From the three types of discriminating power, three corresponding sets of attribute weights are determined and then combined using three coefficients to generate the integrated weighs of attributes. When there is unknown or incomplete information in the assessments, an optimization model is constructed based on the integrated weights to determine the minimum and maximum expected utilities of each alternative. The expected utilities are then used to compare alternatives with the help of Hurwicz rule in which the acceptable optimism degree interval is provided by a decision maker. In particular, the transitivity of the comparison outcomes among three alternatives is theoretically analyzed to avoid the problem of comparison cycle and guarantee the validity of the comparison outcomes.

What we have investigated in this paper is a new attempt to explore the determination of attribute weights by taking into account the differences in both belief degrees in belief distributions over a set of grade and the utilities of the grades simultaneously. This is different from existing studies on how to determine attribute weights from discriminating power in scalar values instead of in distributions (Chin et al. 2015; Deng et al. 2000; Diakoulaki et al. 
1995; Fan et al. 2002; Fu and Wang 2015; Fu and Xu 2016; He et al. 2016; Wang and Luo 2010; Şahin and Liu 2016).

\section{Acknowledgements}

This research is supported by the National Natural Science Foundation of China (Grant Nos. 71622003, 71571060, 71690235, 71690230, 71521001, and 71201043). The second author acknowledges the support by the European Commission under the Grant No. EC-GPF-314836 and the Alliance Manchester Business School Research Support Fund.

\section{Appendix: Proof of Theorems 3-5}

Proof of Theorem 3

Theorem 3. Suppose that $\left[\bar{D}^{-}\left(e_{i}\right), \bar{D}^{+}\left(e_{i}\right)\right](i=1, \ldots, L)$ is obtained from solving the pair of optimization problems in Eqs. (9)-(11) and $\bar{D}^{*}\left(e_{i}\right)$ is a variable limited to $\left[\bar{D}^{-}\left(e_{i}\right), \bar{D}^{+}\left(e_{i}\right)\right]$. Then, $w_{i}^{d}=\frac{\bar{D}^{*}\left(e_{i}\right)}{\sum_{j=1}^{L} \bar{D}^{*}\left(e_{j}\right)}$ is increasing with respect to $\bar{D}^{*}\left(e_{i}\right)$ and decreasing with respect to $\bar{D}^{*}\left(e_{j}\right) \quad(j \neq i)$.

Proof. To focus on the monotonicity of $w_{i}^{d}$ with respect to $\bar{D}^{*}\left(e_{i}\right)$, the derivative of $w_{i}^{d}$ regarding $\bar{D}^{*}\left(e_{i}\right)$ is calculated by

$$
\frac{\partial w_{i}^{d}}{\partial \bar{D}^{*}\left(e_{i}\right)}=\frac{\bar{D}^{*}\left(e_{i}\right)+\sum_{j=1, j \neq i}^{L} \bar{D}^{*}\left(e_{j}\right)-\bar{D}^{*}\left(e_{i}\right)}{\left(\bar{D}^{*}\left(e_{i}\right)+\sum_{j=1, j \neq i}^{L} \bar{D}^{*}\left(e_{j}\right)\right)^{2}}=\frac{\sum_{j=1, j \neq i}^{L} \bar{D}^{*}\left(e_{j}\right)}{\left(\bar{D}^{*}\left(e_{i}\right)+\sum_{j=1, j \neq i}^{L} \bar{D}^{*}\left(e_{j}\right)\right)^{2}} .
$$

Because $\bar{D}^{*}\left(e_{i}\right) \geq 0$ and $\bar{D}^{*}\left(e_{j}\right) \geq 0(j \neq i)$, which can be found from Definitions 1-2 and Eqs. (9)-(11), we have $\frac{\partial w_{i}^{d}}{\partial \bar{D}^{*}\left(e_{i}\right)} \geq 0$, which verifies that the value of $w_{i}^{d}$ will become larger with the increase in $\bar{D}^{*}\left(e_{i}\right)$.

On the other hand, to analyze the monotonicity of $w_{i}^{d}$ with respect to $\bar{D}^{*}\left(e_{j}\right) \quad(j \neq i)$, we calculate the derivative of $w_{i}^{d}$ regarding $\bar{D}^{*}\left(e_{j}\right)$, which is

$$
\frac{\partial w_{i}^{d}}{\partial \bar{D}^{*}\left(e_{j}\right)}=\frac{-\bar{D}^{*}\left(e_{i}\right)}{\left(\bar{D}^{*}\left(e_{i}\right)+\sum_{j=1, j \neq i}^{L} \bar{D}^{*}\left(e_{j}\right)\right)^{2}} \text {. }
$$

This shows that $\frac{\partial w_{i}^{d}}{\partial \bar{D}^{*}\left(e_{j}\right)} \leq 0$ because $\bar{D}^{*}\left(e_{i}\right) \geq 0$ and $\bar{D}^{*}\left(e_{j}\right) \geq 0(j \neq i)$. As a result, we 
can draw a conclusion that the value of $w_{i}^{d}$ will become smaller with the increase in $\bar{D}^{*}\left(e_{j}\right)$ $(j \neq i)$

As a whole, the conclusion in this theorem is verified.

\section{Proof of Theorem 4}

Theorem 4. Given the optimal $\left[u^{-}\left(a_{l}\right), u^{+}\left(a_{l}\right)\right]$ and $\left[u^{-}\left(a_{m}\right), u^{+}\left(a_{m}\right)\right]$ for two alternatives $a_{l}$ and $a_{m}$, suppose that $E\left(a_{l}\right)=\gamma \cdot u^{+}\left(a_{l}\right)+(1-\gamma) \cdot u^{-}\left(a_{l}\right)$ and $E\left(a_{m}\right)=\gamma \cdot u^{+}\left(a_{m}\right)+(1-\gamma) \cdot u^{-}\left(a_{m}\right)$ represent the expected utilities of alternatives $a_{l}$ and $a_{m}$ in Hurwicz rule and $\Delta E\left(a_{l m}\right)=E\left(a_{l}\right)-E\left(a_{m}\right)$ represents the difference between the expected utilities of $a_{l}$ and $a_{m}$, then we have the following conclusions.

(1) When $u^{+}\left(a_{l}\right)>u^{+}\left(a_{m}\right)$ and $u^{-}\left(a_{l}\right)<u^{-}\left(a_{m}\right), \Delta E\left(a_{l m}\right)$ is monotonously increasing with respect to $\gamma$, and it is smaller than, equal to, and larger than 0 when $\gamma$ is limited to $\left[0, \gamma^{*}\right),\left[\gamma^{*}\right.$, $\left.\gamma^{*}\right]$, and $\left(\gamma^{*}, 1\right]$, respectively, where $\gamma^{*}=\frac{u^{-}\left(a_{m}\right)-u^{-}\left(a_{l}\right)}{\left(u^{+}\left(a_{l}\right)-u^{-}\left(a_{l}\right)\right)-\left(u^{+}\left(a_{m}\right)-u^{-}\left(a_{m}\right)\right)}$.

(2) When $u^{+}\left(a_{l}\right)<u^{+}\left(a_{m}\right)$ and $u^{-}\left(a_{l}\right)>u^{-}\left(a_{m}\right), \Delta E\left(a_{l m}\right)$ is monotonously decreasing with respect to $\gamma$, and it is larger than, equal to, and smaller than 0 when $\gamma$ is limited to $\left[0, \gamma^{*}\right),\left[\gamma^{*}\right.$, $\left.\gamma^{*}\right]$, and $\left(\gamma^{*}, 1\right]$, respectively.

Proof. We consider the situation where $u^{+}\left(a_{l}\right)>u^{+}\left(a_{m}\right)$ and $u^{-}\left(a_{l}\right)<u^{-}\left(a_{m}\right)$ first. Under the given conditions, one has

$$
\begin{aligned}
\Delta E\left(a_{l m}\right) & =E\left(a_{l}\right)-E\left(a_{m}\right) \\
& =\gamma \cdot u^{+}\left(a_{l}\right)+(1-\gamma) \cdot u^{-}\left(a_{l}\right)-\left(\gamma \cdot u^{+}\left(a_{m}\right)+(1-\gamma) \cdot u^{-}\left(a_{m}\right)\right) \\
& =\gamma \cdot\left(u^{+}\left(a_{l}\right)-u^{-}\left(a_{l}\right)\right)-\gamma \cdot\left(u^{+}\left(a_{m}\right)-u^{-}\left(a_{m}\right)\right)+\left(u^{-}\left(a_{l}\right)-u^{-}\left(a_{m}\right)\right) \\
& =\gamma \cdot\left(u^{+}\left(a_{l}\right)-u^{+}\left(a_{m}\right)\right)-\gamma \cdot\left(u^{-}\left(a_{l}\right)-u^{-}\left(a_{m}\right)\right)+\left(u^{-}\left(a_{l}\right)-u^{-}\left(a_{m}\right)\right) .
\end{aligned}
$$

Then it is clear that $\Delta E\left(a_{l m}\right)$ is monotonously increasing with respect to $\gamma$. Meanwhile, it is easy to know that $\Delta E\left(a_{l m}\right)<0$ when $\gamma=0$ and $\Delta E\left(a_{l m}\right)>0$ when $\gamma=1$ because $u^{+}\left(a_{l}\right)>u^{+}\left(a_{m}\right)$ and $u^{-}\left(a_{l}\right)<u^{-}\left(a_{m}\right)$. Also, it can be obtained that $\Delta E\left(a_{l m}\right)=0$ when $\gamma=\gamma^{*}=$ $\frac{u^{-}\left(a_{m}\right)-u^{-}\left(a_{l}\right)}{\left(u^{+}\left(a_{l}\right)-u^{-}\left(a_{l}\right)\right)-\left(u^{+}\left(a_{m}\right)-u^{-}\left(a_{m}\right)\right)}$. As a whole, $\Delta E\left(a_{l m}\right)$ is smaller than, equal to, and larger than 0 when $\gamma$ is limited to $\left[0, \gamma^{*}\right),\left[\gamma^{*}, \gamma^{*}\right]$, and $\left(\gamma^{*}, 1\right]$, respectively.

In the situation where $u^{+}\left(a_{l}\right)<u^{+}\left(a_{m}\right)$ and $u^{-}\left(a_{l}\right)>u^{-}\left(a_{m}\right)$, from Eqs. (A.1)-(A.4) one can draw a conclusion that $\Delta E\left(a_{l m}\right)$ is monotonously decreasing with respect to $\gamma$. Meanwhile, it is easily found that $\Delta E\left(a_{l m}\right)>0$ when $\gamma=0$ and $\Delta E\left(a_{l m}\right)<0$ when $\gamma=1$ because $u^{+}\left(a_{l}\right)<u^{+}\left(a_{m}\right)$ and $u^{-}\left(a_{l}\right)>u^{-}\left(a_{m}\right)$. As presented above, $\Delta E\left(a_{l m}\right)$ is equal to 0 when $\gamma=\gamma^{*}=$ 
$\frac{u^{-}\left(a_{m}\right)-u^{-}\left(a_{l}\right)}{\left(u^{+}\left(a_{l}\right)-u^{-}\left(a_{l}\right)\right)-\left(u^{+}\left(a_{m}\right)-u^{-}\left(a_{m}\right)\right)}$. As a whole, $\Delta E\left(a_{l m}\right)$ is larger than, equal to, and smaller than 0 when $\gamma$ is limited to $\left[0, \gamma^{*}\right),\left[\gamma^{*}, \gamma^{*}\right]$, and $\left(\gamma^{*}, 1\right]$, respectively.

From the above analyses, the conclusion in this theorem is verified.

\section{Proof of Theorem 5}

Theorem 5. Given the optimal $\left[u^{-}\left(a_{l}\right), u^{+}\left(a_{l}\right)\right],\left[u^{-}\left(a_{m}\right), u^{+}\left(a_{m}\right)\right]$, and $\left[u^{-}\left(a_{k}\right), u^{+}\left(a_{k}\right)\right]$ for three alternatives $a_{l}, a_{m}$, and $a_{k}$, suppose that $a_{l} \succ a_{m}$ and $a_{m} \succ a_{k}$ in accordance with Definition 5 on the condition that $\left[\gamma^{-}, \gamma^{+}\right]$is provided, then we have $a_{l} \succ a_{k}$.

Proof. When $u^{+}\left(a_{l}\right)>u^{+}\left(a_{m}\right), u^{+}\left(a_{m}\right)>u^{+}\left(a_{k}\right), u^{-}\left(a_{l}\right)>u^{-}\left(a_{m}\right)$, and $u^{-}\left(a_{m}\right)>u^{-}\left(a_{k}\right)$, the conclusion in this theorem is clear to hold. In the following, we discuss other situations.

(1) $u^{+}\left(a_{l}\right)>u^{+}\left(a_{m}\right)$ and $u^{-}\left(a_{l}\right)>u^{-}\left(a_{m}\right)$

In this situation, $a_{l} \succ a_{m}$ always holds no matter whatever the optimism degree $\gamma$ is set as. Under the conditions, we focus on the relationship between $\left[u^{-}\left(a_{m}\right), u^{+}\left(a_{m}\right)\right]$ and $\left[u^{-}\left(a_{k}\right), u^{+}\left(a_{k}\right)\right]$ to guarantee the constraint of $a_{l} \succ a_{k}$.

1) $u^{+}\left(a_{m}\right)>u^{+}\left(a_{k}\right)$ and $u^{-}\left(a_{m}\right)<u^{-}\left(a_{k}\right)$

In accordance with Definition 5, when $\left[\gamma^{-}, \gamma^{+}\right] \subset\left(\gamma_{m k}^{*}, 1\right]$ with $\gamma_{m k}^{*}=$ $\frac{u^{-}\left(a_{k}\right)-u^{-}\left(a_{m}\right)}{\left(u^{+}\left(a_{m}\right)-u^{-}\left(a_{m}\right)\right)-\left(u^{+}\left(a_{k}\right)-u^{-}\left(a_{k}\right)\right)}$, we have $a_{m} \succ a_{k}$. It can be known from $\gamma_{m k}^{*}=$ $\frac{u^{-}\left(a_{k}\right)-u^{-}\left(a_{m}\right)}{\left(u^{+}\left(a_{m}\right)-u^{-}\left(a_{m}\right)\right)-\left(u^{+}\left(a_{k}\right)-u^{-}\left(a_{k}\right)\right)}$ that $\gamma_{m k}^{*}=\frac{1}{\frac{u^{+}\left(a_{m}\right)-u^{+}\left(a_{k}\right)}{u^{-}\left(a_{k}\right)-u^{-}\left(a_{m}\right)}+1}$, which indicates that $\gamma_{m k}^{*}$ is monotonously decreasing with respect to $u^{+}\left(a_{m}\right)$ and $u^{-}\left(a_{m}\right)$. From this fact, we know that $\gamma_{l k}^{*}<\gamma_{m k}^{*}$ when $u^{+}\left(a_{l}\right)>u^{+}\left(a_{m}\right)$ and $u^{-}\left(a_{l}\right)>u^{-}\left(a_{m}\right)$, which results in $\left[\gamma^{-}, \gamma^{+}\right] \subset\left(\gamma_{l k}^{*}, 1\right]$ and further $a_{l} \succ a_{k}$.

On the other hand, when $\gamma_{m k}^{*}$ is limited to $\left[\gamma^{-}, \gamma^{+}\right], \gamma_{m k}^{*}-\gamma^{-}<\gamma^{+}-\gamma_{m k}^{*}$ is needed to guarantee $a_{m} \succ a_{k}$ in accordance with Definition 5. From the fact that $\gamma_{l k}^{*}<\gamma_{m k}^{*}$, as mentioned above, we can obtain that $\gamma_{l k}^{*}-\gamma^{-}<\gamma^{+}-\gamma_{l k}^{*}$ and thus $a_{l} \succ a_{k}$.

2) $u^{+}\left(a_{m}\right)<u^{+}\left(a_{k}\right)$ and $u^{-}\left(a_{m}\right)>u^{-}\left(a_{k}\right)$ 
When $u^{+}\left(a_{m}\right)<u^{+}\left(a_{k}\right)$ and $u^{-}\left(a_{m}\right)>u^{-}\left(a_{k}\right)$, from $\gamma_{m k}^{*}=\frac{1}{\frac{u^{+}\left(a_{k}\right)-u^{+}\left(a_{m}\right)}{u^{-}\left(a_{m}\right)-u^{-}\left(a_{k}\right)}+1}$ it can be deduced that $\gamma_{m k}^{*}$ is monotonously increasing with respect to $u^{+}\left(a_{m}\right)$ and $u^{-}\left(a_{m}\right)$, which results in $\gamma_{l k}^{*}>\gamma_{m k}^{*}$ because $u^{+}\left(a_{l}\right)>u^{+}\left(a_{m}\right)$ and $u^{-}\left(a_{l}\right)>u^{-}\left(a_{m}\right)$. From $\gamma_{l k}^{*}>\gamma_{m k}^{*}$ we can know that $\left[\gamma^{-}, \gamma^{+}\right] \subset\left[0, \gamma_{l k}^{*}\right)$ or $\gamma_{l k}^{*} \in\left[\gamma^{-}, \gamma^{+}\right]$with $\gamma_{l k}^{*}-\gamma^{-}>\gamma^{+}-\gamma_{l k}^{*}$ always holds, which results in $a_{l} \succ a_{k}$ in accordance with Definition 5.

(2) $u^{+}\left(a_{l}\right)>u^{+}\left(a_{m}\right)$ and $u^{-}\left(a_{l}\right)<u^{-}\left(a_{m}\right)$

In this situation, $a_{l} \succ a_{m}$ holds when $\left[\gamma^{-}, \gamma^{+}\right] \subset\left(\gamma_{l m}^{*}, 1\right]$ with $\gamma_{l m}^{*}=$ $\frac{u^{-}\left(a_{m}\right)-u^{-}\left(a_{l}\right)}{\left(u^{+}\left(a_{l}\right)-u^{-}\left(a_{l}\right)\right)-\left(u^{+}\left(a_{m}\right)-u^{-}\left(a_{m}\right)\right)}$ or $\gamma_{l m}^{*} \in\left[\gamma^{-}, \gamma^{+}\right]$with $\gamma_{l m}^{*}-\gamma^{-}<\gamma^{+}-\gamma_{l m}^{*}$ holds in accordance with Definition 5. Under the conditions, we focus on the following three relationships between $\left[u^{-}\left(a_{m}\right), u^{+}\left(a_{m}\right)\right]$ and $\left[u^{-}\left(a_{k}\right), u^{+}\left(a_{k}\right)\right]$ to guarantee the given constraint of $a_{m} \succ a_{k}$.

1) $u^{+}\left(a_{m}\right)>u^{+}\left(a_{k}\right)$ and $u^{-}\left(a_{m}\right)>u^{-}\left(a_{k}\right)$

Under the conditions $a_{m} \succ a_{k}$ is clear to hold. As $\gamma_{l m}^{*}=\frac{1}{\frac{u^{+}\left(a_{l}\right)-u^{+}\left(a_{m}\right)}{u^{-}\left(a_{m}\right)-u^{-}\left(a_{l}\right)}+1}$ when $u^{+}\left(a_{l}\right)>u^{+}\left(a_{m}\right)$ and $u^{-}\left(a_{l}\right)<u^{-}\left(a_{m}\right)$, it can be easily found that $\gamma_{l m}^{*}$ is monotonously increasing with respect to $u^{+}\left(a_{m}\right)$ and $u^{-}\left(a_{m}\right)$. From this we have $\gamma_{l k}^{*}<\gamma_{l m}^{*}$ when $u^{+}\left(a_{m}\right)>u^{+}\left(a_{k}\right)$ and $u^{-}\left(a_{m}\right)>u^{-}\left(a_{k}\right)$, which indicates that $\left[\gamma^{-}, \gamma^{+}\right] \subset\left(\gamma_{l k}^{*}, 1\right]$ or $\gamma_{l k}^{*} \in\left[\gamma^{-}, \gamma^{+}\right]$with $\gamma_{l k}^{*}-\gamma^{-}<\gamma^{+}$ - $\gamma_{l k}^{*}$ holds. As $u^{+}\left(a_{l}\right)>u^{+}\left(a_{m}\right)>u^{+}\left(a_{k}\right), a_{l} \succ a_{k}$ holds when $u^{-}\left(a_{l}\right)<u^{-}\left(a_{k}\right)$ in accordance with Definition 5. Also it is clear that $a_{l} \succ a_{k}$ when $u^{-}\left(a_{l}\right)>u^{-}\left(a_{k}\right)$.

2) $u^{+}\left(a_{m}\right)>u^{+}\left(a_{k}\right)$ and $u^{-}\left(a_{m}\right)<u^{-}\left(a_{k}\right)$

As presented above, under the conditions $\left[\gamma^{-}, \gamma^{+}\right] \subset\left(\gamma_{m k}^{*}, 1\right]$ or $\gamma_{m k}^{*} \in\left[\gamma^{-}, \gamma^{+}\right]$with $\gamma_{m k}^{*}$ $-\gamma^{-}<\gamma^{+}-\gamma_{m k}^{*}$ is needed to guarantee $a_{m} \succ a_{k}$, while $\left[\gamma^{-}, \gamma^{+}\right] \subset\left(\gamma_{l m}^{*}, 1\right]$ or $\gamma_{l m}^{*} \in\left[\gamma^{-}, \gamma^{+}\right]$ with $\gamma_{l m}^{*}-\gamma^{-}<\gamma^{+}-\gamma_{l m}^{*}$ is needed to guarantee $a_{l} \succ a_{m}$.

Assume that $\left[\gamma^{-}, \gamma^{+}\right] \subset\left(\gamma_{m k}^{*}, 1\right]$ and $\left[\gamma^{-}, \gamma^{+}\right] \subset\left(\gamma_{l m}^{*}, 1\right]$ first, then there are two possible 
cases where $\gamma_{l m}^{*}<\gamma_{m k}^{*}$ and $\gamma_{l m}^{*}>\gamma_{m k}^{*}$. Without loss of generality, suppose that $\gamma_{l m}^{*}<$ $\gamma_{m k}^{*}$. As $\gamma_{l m}^{*}=\frac{u^{-}\left(a_{m}\right)-u^{-}\left(a_{l}\right)}{\left(u^{+}\left(a_{l}\right)-u^{-}\left(a_{l}\right)\right)-\left(u^{+}\left(a_{m}\right)-u^{-}\left(a_{m}\right)\right)}=\frac{1}{\frac{u^{+}\left(a_{l}\right)-u^{+}\left(a_{m}\right)}{u^{-}\left(a_{m}\right)-u^{-}\left(a_{l}\right)}+1}$ and $\gamma_{m k}^{*}=$
$\frac{u^{-}\left(a_{k}\right)-u^{-}\left(a_{m}\right)}{\left(u^{+}\left(a_{m}\right)-u^{-}\left(a_{m}\right)\right)-\left(u^{+}\left(a_{k}\right)-u^{-}\left(a_{k}\right)\right)}=\frac{1}{\frac{u^{+}\left(a_{m}\right)-u^{+}\left(a_{k}\right)}{u^{-}\left(a_{k}\right)-u^{-}\left(a_{m}\right)}+1}$, from $\gamma_{l m}^{*}<\gamma_{m k}^{*}$ it can be deduced that $\frac{1}{\frac{u^{+}\left(a_{l}\right)-u^{+}\left(a_{m}\right)}{u^{-}\left(a_{m}\right)-u^{-}\left(a_{l}\right)}+1}<\frac{1}{\frac{u^{+}\left(a_{m}\right)-u^{+}\left(a_{k}\right)}{u^{-}\left(a_{k}\right)-u^{-}\left(a_{m}\right)}+1}$ and further

$u^{+}\left(a_{l}\right) \cdot u^{-}\left(a_{k}\right)-u^{+}\left(a_{l}\right) \cdot u^{-}\left(a_{m}\right)-u^{+}\left(a_{m}\right) \cdot u^{-}\left(a_{k}\right)>u^{+}\left(a_{k}\right) \cdot u^{-}\left(a_{l}\right)-u^{+}\left(a_{k}\right) \cdot u^{-}\left(a_{m}\right)-u^{+}\left(a_{m}\right) \cdot u^{-}\left(a_{l}\right)$.

On the other hand, it can be similarly obtained that $\gamma_{l k}^{*}=$ $\frac{u^{-}\left(a_{k}\right)-u^{-}\left(a_{l}\right)}{\left(u^{+}\left(a_{l}\right)-u^{-}\left(a_{l}\right)\right)-\left(u^{+}\left(a_{k}\right)-u^{-}\left(a_{k}\right)\right)}=\frac{1}{\frac{u^{+}\left(a_{l}\right)-u^{+}\left(a_{k}\right)}{u^{-}\left(a_{k}\right)-u^{-}\left(a_{l}\right)}+1}$. On the assumption that $\gamma_{l k}^{*}<$ $\gamma_{m k}^{*}$, i.e., $\frac{1}{\frac{u^{+}\left(a_{l}\right)-u^{+}\left(a_{k}\right)}{u^{-}\left(a_{k}\right)-u^{-}\left(a_{l}\right)}+1}<\frac{1}{\frac{u^{+}\left(a_{m}\right)-u^{+}\left(a_{k}\right)}{u^{-}\left(a_{k}\right)-u^{-}\left(a_{m}\right)}+1}$ we have

$u^{+}\left(a_{l}\right) \cdot u^{-}\left(a_{k}\right)-u^{+}\left(a_{l}\right) \cdot u^{-}\left(a_{m}\right)+u^{+}\left(a_{k}\right) \cdot u^{-}\left(a_{m}\right)>u^{+}\left(a_{m}\right) \cdot u^{-}\left(a_{k}\right)-u^{+}\left(a_{m}\right) \cdot u^{-}\left(a_{l}\right)+u^{+}\left(a_{k}\right) \cdot u^{-}\left(a_{l}\right)$.

It is easy to find that Eq. (A.5) is equivalent to Eq. (A.6), so $\gamma_{l k}^{*}<\gamma_{m k}^{*}$ certainly holds when $\gamma_{l m}^{*}<\gamma_{m k}^{*}$ is assumed, which results in $\left[\gamma^{-}, \gamma^{+}\right] \subset\left(\gamma_{l k}^{*}, 1\right]$ and $a_{l} \succ a_{k}$. When we suppose that $\gamma_{l m}^{*}>\gamma_{m k}^{*}$, we can similarly conclude that $\gamma_{l k}^{*}<\gamma_{l m}^{*}$ and $a_{l} \succ a_{k}$.

Secondly, assume that $\left[\gamma^{-}, \gamma^{+}\right] \subset\left(\gamma_{m k}^{*}, 1\right]$ and $\gamma_{l m}^{*} \in\left[\gamma^{-}, \gamma^{+}\right]$with $\gamma_{l m}^{*}-\gamma^{-}<\gamma^{+}-\gamma_{l m}^{*}$. On this assumption, it is clear that $\gamma_{m k}^{*}<\gamma_{l m}^{*}$. As analyzed above, we can know $\gamma_{l k}^{*}<\gamma_{l m}^{*}$ from $\gamma_{m k}^{*}<\gamma_{l m}^{*}$. If $\gamma_{l k}^{*} \in\left[\gamma^{-}, \gamma^{+}\right]$, then we clearly have $\gamma_{l k}^{*}-\gamma^{-}<\gamma^{+}-\gamma_{l k}^{*}$ and $a_{l} \succ a_{k}$. When $\gamma_{l k}^{*} \notin\left[\gamma^{-}, \gamma^{+}\right]$, we certainly have $\left[\gamma^{-}, \gamma^{+}\right] \subset\left(\gamma_{l k}^{*}, 1\right]$ and $a_{l} \succ a_{k}$.

Thirdly, on the assumption that $\gamma_{m k}^{*} \in\left[\gamma^{-}, \gamma^{+}\right]$with $\gamma_{m k}^{*}-\gamma^{-}<\gamma^{+}-\gamma_{m k}^{*}$ and $\left[\gamma^{-}, \gamma^{+}\right] \subset$ $\left(\gamma_{l m}^{*}, 1\right]$, we have $\gamma_{l m}^{*}<\gamma_{m k}^{*}$ and its equivalent $\gamma_{l k}^{*}<\gamma_{m k}^{*}$, from which the conclusion that 
$a_{l} \succ a_{k}$ can be drawn in accordance with the above analysis.

Fourthly, on the assumption that $\gamma_{m k}^{*} \in\left[\gamma^{-}, \gamma^{+}\right]$with $\gamma_{m k}^{*}-\gamma^{-}<\gamma^{+}-\gamma_{m k}^{*}$ and $\gamma_{l m}^{*} \in$ $\left[\gamma^{-}, \gamma^{+}\right]$with $\gamma_{l m}^{*}-\gamma^{-}<\gamma^{+}-\gamma_{l m}^{*}$, as $\gamma_{m k}^{*}<\gamma_{l m}^{*}$ is equivalent to $\gamma_{l k}^{*}<\gamma_{l m}^{*}$ and $\gamma_{l m}^{*}<$ $\gamma_{m k}^{*}$ is equivalent to $\gamma_{l k}^{*}<\gamma_{m k}^{*}$, one of $\gamma_{l k}^{*} \in\left[\gamma^{-}, \gamma^{+}\right]$with $\gamma_{l k}^{*}-\gamma^{-}<\gamma^{+}-\gamma_{l k}^{*}$ and $\left[\gamma^{-}, \gamma^{+}\right]$ $\subset\left(\gamma_{l k}^{*}, 1\right]$ always holds. As a result, we always have $a_{l} \succ a_{k}$.

3) $u^{+}\left(a_{m}\right)<u^{+}\left(a_{k}\right)$ and $u^{-}\left(a_{m}\right)>u^{-}\left(a_{k}\right)$

Under the conditions $\left[\gamma^{-}, \gamma^{+}\right] \subset\left[0, \gamma_{m k}^{*}\right)$ or $\gamma_{m k}^{*} \in\left[\gamma^{-}, \gamma^{+}\right]$with $\gamma_{m k}^{*}-\gamma^{-}>\gamma^{+}-\gamma_{m k}^{*}$ is needed to guarantee $a_{m} \succ a_{k}$, while $\left[\gamma^{-}, \gamma^{+}\right] \subset\left(\gamma_{l m}^{*}, 1\right]$ or $\gamma_{l m}^{*} \in\left[\gamma^{-}, \gamma^{+}\right]$with $\gamma_{l m}^{*}-\gamma^{-}<$ $\gamma^{+}-\gamma_{l m}^{*}$ is needed to guarantee $a_{l} \succ a_{m}$.

Firstly, assume that $\left[\gamma^{-}, \gamma^{+}\right] \subset\left[0, \gamma_{m k}^{*}\right)$ and $\left[\gamma^{-}, \gamma^{+}\right] \subset\left(\gamma_{l m}^{*}, 1\right]$. On this assumption, it is needed that $\gamma_{l m}^{*}<\gamma_{m k}^{*}$. With the consideration of $u^{+}\left(a_{l}\right)>u^{+}\left(a_{m}\right), u^{-}\left(a_{l}\right)<u^{-}\left(a_{m}\right), u^{+}\left(a_{m}\right)<$ $u^{+}\left(a_{k}\right)$, and $u^{-}\left(a_{m}\right)>u^{-}\left(a_{k}\right)$, it can be obtained from $\gamma_{l m}^{*}<\gamma_{m k}^{*}$ that $\frac{1}{\frac{u^{+}\left(a_{l}\right)-u^{+}\left(a_{m}\right)}{u^{-}\left(a_{m}\right)-u^{-}\left(a_{l}\right)}+1}<$ $\frac{1}{\frac{u^{+}\left(a_{k}\right)-u^{+}\left(a_{m}\right)}{u^{-}\left(a_{m}\right)-u^{-}\left(a_{k}\right)}+1}$, which further deduces that

$$
u^{+}\left(a_{l}\right) \cdot u^{-}\left(a_{m}\right)-u^{+}\left(a_{l}\right) \cdot u^{-}\left(a_{k}\right)+u^{+}\left(a_{m}\right) \cdot u^{-}\left(a_{k}\right)>u^{+}\left(a_{k}\right) \cdot u^{-}\left(a_{m}\right)-u^{+}\left(a_{k}\right) \cdot u^{-}\left(a_{l}\right)+u^{+}\left(a_{m}\right) \cdot u^{-}\left(a_{l}\right) .
$$

Meanwhile, the relationship between $\left[u^{-}\left(a_{l}\right), u^{+}\left(a_{l}\right)\right]$ and $\left[u^{-}\left(a_{k}\right), u^{+}\left(a_{k}\right)\right]$ cannot be obtained from $u^{+}\left(a_{l}\right)>u^{+}\left(a_{m}\right), u^{-}\left(a_{l}\right)<u^{-}\left(a_{m}\right), u^{+}\left(a_{m}\right)<u^{+}\left(a_{k}\right)$, and $u^{-}\left(a_{m}\right)>u^{-}\left(a_{k}\right)$. As such, four possible relationships need to be analyzed, including $u^{+}\left(a_{l}\right)>u^{+}\left(a_{k}\right)$ and $u^{-}\left(a_{l}\right)>u^{-}\left(a_{k}\right), u^{+}\left(a_{l}\right)$ $<u^{+}\left(a_{k}\right)$ and $u^{-}\left(a_{l}\right)<u^{-}\left(a_{k}\right), u^{+}\left(a_{l}\right)>u^{+}\left(a_{k}\right)$ and $u^{-}\left(a_{l}\right)<u^{-}\left(a_{k}\right)$, and $u^{+}\left(a_{l}\right)<u^{+}\left(a_{k}\right)$ and $u^{-}\left(a_{l}\right)>$ $u^{-}\left(a_{k}\right)$. To analyze the first two relationships, $u^{+}\left(a_{k}\right) \cdot u^{-}\left(a_{k}\right)$ is added on the two sides of Eq. (A.7) to transform this equation into

$$
\left(u^{+}\left(a_{l}\right)-u^{+}\left(a_{k}\right)\right) \cdot\left(u^{-}\left(a_{m}\right)-u^{-}\left(a_{k}\right)\right)>\left(u^{+}\left(a_{m}\right)-u^{+}\left(a_{k}\right)\right) \cdot\left(u^{-}\left(a_{l}\right)-u^{-}\left(a_{k}\right)\right) .
$$

For $u^{-}\left(a_{m}\right)-u^{-}\left(a_{k}\right)>0$ and $u^{+}\left(a_{m}\right)-u^{+}\left(a_{k}\right)<0$ from the given conditions $u^{+}\left(a_{m}\right)<u^{+}\left(a_{k}\right)$ and $u^{-}\left(a_{m}\right)>u^{-}\left(a_{k}\right)$, Eq. (A.8) is true when $u^{+}\left(a_{l}\right)>u^{+}\left(a_{k}\right)$ and $u^{-}\left(a_{l}\right)>u^{-}\left(a_{k}\right)$ but false when $u^{+}\left(a_{l}\right)$ $<u^{+}\left(a_{k}\right)$ and $u^{-}\left(a_{l}\right)<u^{-}\left(a_{k}\right)$. As a result, to make Eq. (A.8) hold, $a_{l} \succ a_{k}$ is certainly true in the first relationship. The second relationship is incorrect for Eq. (A.8) and thus omitted. 
In the third relationship of $u^{+}\left(a_{l}\right)>u^{+}\left(a_{k}\right)$ and $u^{-}\left(a_{l}\right)<u^{-}\left(a_{k}\right)$, suppose that $\gamma_{l k}^{*}<\gamma_{l m}^{*}$, then

$$
\begin{aligned}
& \text { we have } \frac{1}{\frac{u^{+}\left(a_{l}\right)-u^{+}\left(a_{k}\right)}{u^{-}\left(a_{k}\right)-u^{-}\left(a_{l}\right)}+1}<\frac{1}{\frac{u^{+}\left(a_{l}\right)-u^{+}\left(a_{m}\right)}{u^{-}\left(a_{m}\right)-u^{-}\left(a_{l}\right)}+1} \text { and further } \\
& u^{+}\left(a_{l}\right) \cdot u^{-}\left(a_{m}\right)-u^{+}\left(a_{k}\right) \cdot u^{-}\left(a_{m}\right)+u^{+}\left(a_{k}\right) \cdot u^{-}\left(a_{l}\right)>u^{+}\left(a_{l}\right) \cdot u^{-}\left(a_{k}\right)-u^{+}\left(a_{m}\right) \cdot u^{-}\left(a_{k}\right)+u^{+}\left(a_{m}\right) \cdot u^{-}\left(a_{l}\right) .
\end{aligned}
$$

As Eq. (A.7) is equivalent to Eq. (A.9), $\gamma_{l k}^{*}<\gamma_{l m}^{*}$ is equivalent to $\gamma_{l m}^{*}<\gamma_{m k}^{*}$, which means that $a_{l} \succ a_{k}$.

Finally, in the fourth relationship of $u^{+}\left(a_{l}\right)<u^{+}\left(a_{k}\right)$ and $u^{-}\left(a_{l}\right)>u^{-}\left(a_{k}\right)$, suppose that $\gamma_{m k}^{*}<$

$$
\gamma_{l k}^{*} \text {, then we have } \frac{1}{\frac{u^{+}\left(a_{k}\right)-u^{+}\left(a_{m}\right)}{u^{-}\left(a_{m}\right)-u^{-}\left(a_{k}\right)}+1}<\frac{1}{\frac{u^{+}\left(a_{k}\right)-u^{+}\left(a_{l}\right)}{u^{-}\left(a_{l}\right)-u^{-}\left(a_{k}\right)}+1} \text { and further }
$$

$$
u^{+}\left(a_{k}\right) \cdot u^{-}\left(a_{l}\right)-u^{+}\left(a_{m}\right) \cdot u^{-}\left(a_{l}\right)+u^{+}\left(a_{m}\right) \cdot u^{-}\left(a_{k}\right)>u^{+}\left(a_{k}\right) \cdot u^{-}\left(a_{m}\right)-u^{+}\left(a_{l}\right) \cdot u^{-}\left(a_{m}\right)+u^{+}\left(a_{l}\right) \cdot u^{-}\left(a_{k}\right) .
$$

From the equivalence between Eqs. (A.7) and (A.10), we derive the equivalence between $\gamma_{m k}^{*}<\gamma_{l k}^{*}$ and $\gamma_{l m}^{*}<\gamma_{m k}^{*}$, which results in $a_{l} \succ a_{k}$.

When one of three conditions are satisfied, i.e., $\left[\gamma^{-}, \gamma^{+}\right] \subset\left[0, \gamma_{m k}^{*}\right)$ and $\gamma_{l m}^{*} \in\left[\gamma^{-}, \gamma^{+}\right]$ with $\gamma_{l m}^{*}-\gamma^{-}<\gamma^{+}-\gamma_{l m}^{*}, \gamma_{m k}^{*} \in\left[\gamma^{-}, \gamma^{+}\right]$with $\gamma_{m k}^{*}-\gamma^{-}>\gamma^{+}-\gamma_{m k}^{*}$ and $\left[\gamma^{-}, \gamma^{+}\right] \subset\left(\gamma_{l m}^{*}\right.$, 1], and $\gamma_{m k}^{*} \in\left[\gamma^{-}, \gamma^{+}\right]$with $\gamma_{m k}^{*}-\gamma^{-}>\gamma^{+}-\gamma_{m k}^{*}$ and $\gamma_{l m}^{*} \in\left[\gamma^{-}, \gamma^{+}\right]$with $\gamma_{l m}^{*}-\gamma^{-}<\gamma^{+}-$ $\gamma_{l m}^{*}, \gamma_{l m}^{*}<\gamma_{m k}^{*}$ is always required, which results in $a_{l} \succ a_{k}$, as analyzed above.

(3) $u^{+}\left(a_{l}\right)<u^{+}\left(a_{m}\right)$ and $u^{-}\left(a_{l}\right)>u^{-}\left(a_{m}\right)$

In this situation, $a_{l} \succ a_{m}$ holds when $\left[\gamma^{-}, \gamma^{+}\right] \subset\left[0, \gamma_{l m}^{*}\right)$ or $\gamma_{l m}^{*} \in\left[\gamma^{-}, \gamma^{+}\right]$with $\gamma_{l m}^{*}-$ $\gamma^{-}>\gamma^{+}-\gamma_{l m}^{*}$. Under the conditions, we focus on the following three relationships between $\left[u^{-}\left(a_{m}\right), u^{+}\left(a_{m}\right)\right]$ and $\left[u^{-}\left(a_{k}\right), u^{+}\left(a_{k}\right)\right]$ to guarantee the constraint of $a_{m} \succ a_{k}$.

1) $u^{+}\left(a_{m}\right)>u^{+}\left(a_{k}\right)$ and $u^{-}\left(a_{m}\right)>u^{-}\left(a_{k}\right)$

Under the conditions, $a_{m} \succ a_{k}$ always holds. Because $\gamma_{l m}^{*}=$ $\frac{u^{-}\left(a_{m}\right)-u^{-}\left(a_{l}\right)}{\left(u^{+}\left(a_{l}\right)-u^{-}\left(a_{l}\right)\right)-\left(u^{+}\left(a_{m}\right)-u^{-}\left(a_{m}\right)\right)}=\frac{1}{\frac{u^{+}\left(a_{m}\right)-u^{+}\left(a_{l}\right)}{u^{-}\left(a_{l}\right)-u^{-}\left(a_{m}\right)}+1}$, it is easy to know that $\gamma_{l m}^{*}$ is monotonously decreasing with respect to $u^{+}\left(a_{m}\right)$ and $u^{-}\left(a_{m}\right)$. This can deduce that $\gamma_{l m}^{*}<\gamma_{l k}^{*}$ 
and further $\left[\gamma^{-}, \gamma^{+}\right] \subset\left[0, \gamma_{l k}^{*}\right)$ or $\gamma_{l k}^{*} \in\left[\gamma^{-}, \gamma^{+}\right]$with $\gamma_{l k}^{*}-\gamma^{-}>\gamma^{+}-\gamma_{l k}^{*}$. As $u^{+}\left(a_{l}\right)<$ $u^{+}\left(a_{m}\right), u^{-}\left(a_{l}\right)>u^{-}\left(a_{m}\right), u^{+}\left(a_{m}\right)>u^{+}\left(a_{k}\right)$, and $u^{-}\left(a_{m}\right)>u^{-}\left(a_{k}\right)$, when $u^{+}\left(a_{l}\right)<u^{+}\left(a_{k}\right), a_{l} \succ a_{k}$ holds in accordance with Definition 5. Also $a_{l} \succ a_{k}$ clearly holds when $u^{+}\left(a_{l}\right)>u^{+}\left(a_{k}\right)$.

2) $u^{+}\left(a_{m}\right)>u^{+}\left(a_{k}\right)$ and $u^{-}\left(a_{m}\right)<u^{-}\left(a_{k}\right)$

Under the conditions, $\left[\gamma^{-}, \gamma^{+}\right] \subset\left[0, \gamma_{l m}^{*}\right.$ ) or $\gamma_{l m}^{*} \in\left[\gamma^{-}, \gamma^{+}\right]$with $\gamma_{l m}^{*}-\gamma^{-}>\gamma^{+}-\gamma_{l m}^{*}$ is needed to guarantee $a_{l} \succ a_{m}$, while $\left[\gamma^{-}, \gamma^{+}\right] \subset\left(\gamma_{m k}^{*}, 1\right]$ or $\gamma_{m k}^{*} \in\left[\gamma^{-}, \gamma^{+}\right]$with $\gamma_{m k}^{*}-\gamma^{-}<$ $\gamma^{+}-\gamma_{m k}^{*}$ is needed to guarantee $a_{m} \succ a_{k}$.

Assume that $\left[\gamma^{-}, \gamma^{+}\right] \subset\left[0, \gamma_{l m}^{*}\right)$ and $\left[\gamma^{-}, \gamma^{+}\right] \subset\left(\gamma_{m k}^{*}, 1\right]$ first. On this assumption, it can be known that $\gamma_{m k}^{*}<\gamma_{l m}^{*}$, which deduces that $\frac{1}{\frac{u^{+}\left(a_{m}\right)-u^{+}\left(a_{k}\right)}{u^{-}\left(a_{k}\right)-u^{-}\left(a_{m}\right)}+1}<\frac{1}{\frac{u^{+}\left(a_{m}\right)-u^{+}\left(a_{l}\right)}{u^{-}\left(a_{l}\right)-u^{-}\left(a_{m}\right)}+1}$ and further

$$
u^{+}\left(a_{m}\right) \cdot u^{-}\left(a_{l}\right)-u^{+}\left(a_{k}\right) \cdot u^{-}\left(a_{l}\right)+u^{+}\left(a_{k}\right) \cdot u^{-}\left(a_{m}\right)>u^{+}\left(a_{m}\right) \cdot u^{-}\left(a_{k}\right)-u^{+}\left(a_{l}\right) \cdot u^{-}\left(a_{k}\right)+u^{+}\left(a_{l}\right) \cdot u^{-}\left(a_{m}\right) \text {. (A.11) }
$$

Similar to the situation where $u^{+}\left(a_{l}\right)>u^{+}\left(a_{m}\right), u^{-}\left(a_{l}\right)<u^{-}\left(a_{m}\right), u^{+}\left(a_{m}\right)<u^{+}\left(a_{k}\right)$, and $u^{-}\left(a_{m}\right)>$ $u^{-}\left(a_{k}\right)$, the relationship between $\left[u^{-}\left(a_{l}\right), u^{+}\left(a_{l}\right)\right]$ and $\left[u^{-}\left(a_{k}\right), u^{+}\left(a_{k}\right)\right]$ cannot be obtained from $u^{+}\left(a_{l}\right)<u^{+}\left(a_{m}\right), u^{-}\left(a_{l}\right)>u^{-}\left(a_{m}\right), u^{+}\left(a_{m}\right)>u^{+}\left(a_{k}\right)$, and $u^{-}\left(a_{m}\right)<u^{-}\left(a_{k}\right)$. As such, four possible relationships need to be analyzed, including $u^{+}\left(a_{l}\right)>u^{+}\left(a_{k}\right)$ and $u^{-}\left(a_{l}\right)>u^{-}\left(a_{k}\right), u^{+}\left(a_{l}\right)<u^{+}\left(a_{k}\right)$ and $u^{-}\left(a_{l}\right)<u^{-}\left(a_{k}\right), u^{+}\left(a_{l}\right)>u^{+}\left(a_{k}\right)$ and $u^{-}\left(a_{l}\right)<u^{-}\left(a_{k}\right)$, and $u^{+}\left(a_{l}\right)<u^{+}\left(a_{k}\right)$ and $u^{-}\left(a_{l}\right)>u^{-}\left(a_{k}\right)$. To analyze the first two relationships, $u^{+}\left(a_{k}\right) \cdot u^{-}\left(a_{k}\right)$ is added on the two sides of Eq. (A.11) to transform this equation into

$$
\left(u^{+}\left(a_{m}\right)-u^{+}\left(a_{k}\right)\right) \cdot\left(u^{-}\left(a_{l}\right)-u^{-}\left(a_{k}\right)\right)>\left(u^{+}\left(a_{l}\right)-u^{+}\left(a_{k}\right)\right) \cdot\left(u^{-}\left(a_{m}\right)-u^{-}\left(a_{k}\right)\right) .
$$

For $u^{+}\left(a_{m}\right)-u^{+}\left(a_{k}\right)>0$ and $u^{-}\left(a_{m}\right)-u^{-}\left(a_{k}\right)<0$ from the given conditions $u^{+}\left(a_{m}\right)>u^{+}\left(a_{k}\right)$ and $u^{-}\left(a_{m}\right)<u^{-}\left(a_{k}\right)$, Eq. (A.12) is true when $u^{+}\left(a_{l}\right)>u^{+}\left(a_{k}\right)$ and $u^{-}\left(a_{l}\right)>u^{-}\left(a_{k}\right)$ but false when $u^{+}\left(a_{l}\right)$ $<u^{+}\left(a_{k}\right)$ and $u^{-}\left(a_{l}\right)<u^{-}\left(a_{k}\right)$. As a result, to make Eq. (A.12) hold, $a_{l} \succ a_{k}$ is certainly true in the first relationship. The second relationship is incorrect for Eq. (A.12) and thus omitted.

In the third relationship of $u^{+}\left(a_{l}\right)>u^{+}\left(a_{k}\right)$ and $u^{-}\left(a_{l}\right)<u^{-}\left(a_{k}\right)$, suppose that $\gamma_{l k}^{*}<\gamma_{m k}^{*}$, which deduces that $\frac{1}{\frac{u^{+}\left(a_{l}\right)-u^{+}\left(a_{k}\right)}{u^{-}\left(a_{k}\right)-u^{-}\left(a_{l}\right)}+1}<\frac{1}{\frac{u^{+}\left(a_{m}\right)-u^{+}\left(a_{k}\right)}{u^{-}\left(a_{k}\right)-u^{-}\left(a_{m}\right)}+1}$ and further

$$
u^{+}\left(a_{l}\right) \cdot u^{-}\left(a_{k}\right)-u^{+}\left(a_{l}\right) \cdot u^{-}\left(a_{m}\right)+u^{+}\left(a_{k}\right) \cdot u^{-}\left(a_{m}\right)>u^{+}\left(a_{m}\right) \cdot u^{-}\left(a_{k}\right)-u^{+}\left(a_{m}\right) \cdot u^{-}\left(a_{l}\right)+u^{+}\left(a_{k}\right) \cdot u^{-}\left(a_{l}\right) . \text { (A.13) }
$$

The equivalence between Eqs. (A.11) and (A.13) results in the equivalence between $\gamma_{m k}^{*}<$ 
$\gamma_{l m}^{*}$ and $\gamma_{l k}^{*}<\gamma_{m k}^{*}$, and thus $a_{l} \succ a_{k}$.

Finally, in the fourth relationship of $u^{+}\left(a_{l}\right)<u^{+}\left(a_{k}\right)$ and $u^{-}\left(a_{l}\right)>u^{-}\left(a_{k}\right)$, suppose that $\gamma_{l m}^{*}<$ $\gamma_{l k}^{*}$, which deduces that $\frac{1}{\frac{u^{+}\left(a_{m}\right)-u^{+}\left(a_{l}\right)}{u^{-}\left(a_{l}\right)-u^{-}\left(a_{m}\right)}+1}<\frac{1}{\frac{u^{+}\left(a_{k}\right)-u^{+}\left(a_{l}\right)}{u^{-}\left(a_{l}\right)-u^{-}\left(a_{k}\right)}+1}$ and further

$$
u^{+}\left(a_{m}\right) \cdot u^{-}\left(a_{l}\right)-u^{+}\left(a_{m}\right) \cdot u^{-}\left(a_{k}\right)+u^{+}\left(a_{l}\right) \cdot u^{-}\left(a_{k}\right)>u^{+}\left(a_{k}\right) \cdot u^{-}\left(a_{l}\right)-u^{+}\left(a_{k}\right) \cdot u^{-}\left(a_{m}\right)+u^{+}\left(a_{l}\right) \cdot u^{-}\left(a_{m}\right) .
$$

Eq. (A.14) is clearly equivalent to Eq. (A.11), which results in the equivalence between $\gamma_{m k}^{*}$

$<\gamma_{l m}^{*}$ and $\gamma_{l m}^{*}<\gamma_{l k}^{*}$, and further $a_{l} \succ a_{k}$.

3) $u^{+}\left(a_{m}\right)<u^{+}\left(a_{k}\right)$ and $u^{-}\left(a_{m}\right)>u^{-}\left(a_{k}\right)$

Under the conditions, $\left[\gamma^{-}, \gamma^{+}\right] \subset\left[0, \gamma_{l m}^{*}\right)$ or $\gamma_{l m}^{*} \in\left[\gamma^{-}, \gamma^{+}\right]$with $\gamma_{l m}^{*}-\gamma^{-}>\gamma^{+}-\gamma_{l m}^{*}$ is needed to guarantee $a_{l} \succ a_{m}$, while $\left[\gamma^{-}, \gamma^{+}\right] \subset\left[0, \gamma_{m k}^{*}\right)$ or $\gamma_{m k}^{*} \in\left[\gamma^{-}, \gamma^{+}\right]$with $\gamma_{m k}^{*}-\gamma^{-}>$ $\gamma^{+}-\gamma_{m k}^{*}$ is needed to guarantee $a_{m} \succ a_{k}$.

Firstly, assume that $\left[\gamma^{-}, \gamma^{+}\right] \subset\left[0, \gamma_{l m}^{*}\right)$ and $\left[\gamma^{-}, \gamma^{+}\right] \subset\left[0, \gamma_{m k}^{*}\right)$. There are two possible situations where $\gamma_{l m}^{*}<\gamma_{m k}^{*}$ and $\gamma_{l m}^{*}>\gamma_{m k}^{*}$. Without loss of generality, suppose that $\gamma_{l m}^{*}$ $<\gamma_{m k}^{*}$. Then we have $\frac{1}{\frac{u^{+}\left(a_{m}\right)-u^{+}\left(a_{l}\right)}{u^{-}\left(a_{l}\right)-u^{-}\left(a_{m}\right)}+1}<\frac{1}{\frac{u^{+}\left(a_{k}\right)-u^{+}\left(a_{m}\right)}{u^{-}\left(a_{m}\right)-u^{-}\left(a_{k}\right)}+1}$ and further

$$
\begin{aligned}
& u^{+}\left(a_{l}\right) \cdot u^{-}\left(a_{k}\right)-u^{+}\left(a_{m}\right) \cdot u^{-}\left(a_{k}\right)-u^{+}\left(a_{l}\right) \cdot u^{-}\left(a_{m}\right)> \\
& u^{+}\left(a_{k}\right) \cdot u^{-}\left(a_{l}\right)-u^{+}\left(a_{k}\right) \cdot u^{-}\left(a_{m}\right)-u^{+}\left(a_{m}\right) \cdot u^{-}\left(a_{l}\right) .
\end{aligned}
$$

On the other hand, suppose that $\gamma_{l m}^{*}<\gamma_{l k}^{*}$, which deduces that $\frac{1}{\frac{u^{+}\left(a_{m}\right)-u^{+}\left(a_{l}\right)}{u^{-}\left(a_{l}\right)-u^{-}\left(a_{m}\right)}+1}<$ $\frac{1}{\frac{u^{+}\left(a_{k}\right)-u^{+}\left(a_{l}\right)}{u^{-}\left(a_{l}\right)-u^{-}\left(a_{k}\right)}+1}$ and further

$$
u^{+}\left(a_{m}\right) \cdot u^{-}\left(a_{l}\right)-u^{+}\left(a_{m}\right) \cdot u^{-}\left(a_{k}\right)+u^{+}\left(a_{l}\right) \cdot u^{-}\left(a_{k}\right)>u^{+}\left(a_{k}\right) \cdot u^{-}\left(a_{l}\right)-u^{+}\left(a_{k}\right) \cdot u^{-}\left(a_{m}\right)+u^{+}\left(a_{l}\right) \cdot u^{-}\left(a_{m}\right) \text {. (A.16) }
$$

The equivalence between Eqs. (A.15) and (A.16) results in the equivalence between $\gamma_{l m}^{*}<$ $\gamma_{m k}^{*}$ and $\gamma_{l m}^{*}<\gamma_{l k}^{*}$. From $\gamma_{l m}^{*}<\gamma_{l k}^{*}$ it can be deduced that $a_{l} \succ a_{k}$. When $\gamma_{l m}^{*}>\gamma_{m k}^{*}$, 
the equivalence between $\gamma_{m k}^{*}<\gamma_{l m}^{*}$ and $\gamma_{m k}^{*}<\gamma_{l k}^{*}$ can be similarly found to result in $a_{l}$ $\succ a_{k}$.

Secondly, assume that $\left[\gamma^{-}, \gamma^{+}\right] \subset\left[0, \gamma_{l m}^{*}\right)$ and $\gamma_{m k}^{*} \in\left[\gamma^{-}, \gamma^{+}\right]$with $\gamma_{m k}^{*}-\gamma^{-}>\gamma^{+}-\gamma_{m k}^{*}$, then one has $\gamma_{m k}^{*}<\gamma_{l m}^{*}$ and its equivalent $\gamma_{m k}^{*}<\gamma_{l k}^{*}$. From $\gamma_{m k}^{*}<\gamma_{l k}^{*}$, it can be deduced that $\gamma_{l k}^{*} \in\left[\gamma^{-}, \gamma^{+}\right]$with $\gamma_{l k}^{*}-\gamma^{-}>\gamma^{+}-\gamma_{l k}^{*}$ or $\left[\gamma^{-}, \gamma^{+}\right] \subset\left[0, \gamma_{l k}^{*}\right)$, which results in $a_{l} \succ a_{k}$.

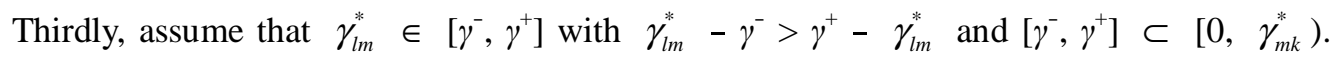

On this assumption, it is required that $\gamma_{l m}^{*}<\gamma_{m k}^{*}$. Then the equivalent of $\gamma_{l m}^{*}<\gamma_{m k}^{*}$, i.e., $\gamma_{l m}^{*}<\gamma_{l k}^{*}$ can deduce that $\gamma_{l k}^{*} \in\left[\gamma^{-}, \gamma^{+}\right]$with $\gamma_{l k}^{*}-\gamma^{-}>\gamma^{+}-\gamma_{l k}^{*}$ or $\left[\gamma^{-}, \gamma^{+}\right] \subset\left[0, \gamma_{l k}^{*}\right)$ and further $a_{l} \succ a_{k}$.

Fourthly, assume that $\gamma_{l m}^{*} \in\left[\gamma^{-}, \gamma^{+}\right]$with $\gamma_{l m}^{*}-\gamma^{-}>\gamma^{+}-\gamma_{l m}^{*}$ and $\gamma_{m k}^{*} \in\left[\gamma^{-}, \gamma^{+}\right]$with

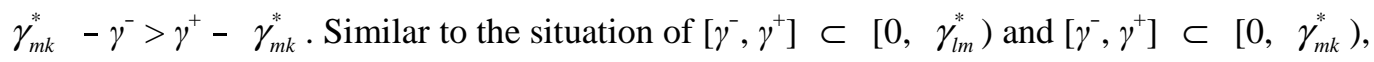
when $\gamma_{l m}^{*}<\gamma_{m k}^{*}$ is assumed, its equivalent $\gamma_{l m}^{*}<\gamma_{l k}^{*}$ results in $\gamma_{l k}^{*} \in\left[\gamma^{-}, \gamma^{+}\right]$with $\gamma_{l k}^{*}$ $-\gamma^{-}>\gamma^{+}-\gamma_{l k}^{*}$ or $\left[\gamma^{-}, \gamma^{+}\right] \subset\left[0, \gamma_{l k}^{*}\right)$ and further $a_{l} \succ a_{k}$. When $\gamma_{m k}^{*}<\gamma_{l m}^{*}$ is assumed, its equivalent $\gamma_{m k}^{*}<\gamma_{l k}^{*}$ can similarly result in $a_{l} \succ a_{k}$.

From the above analyses, the conclusion in this theorem is verified.

\section{References}

Balla V, Gaganis C, Pasiouras F, Zopounidis C (2014). Multicriteria decision aid models for the prediction of securities class actions: evidence from the banking sector. OR Spectrum 36: $57-72$.

Barron FH, Barrett BE (1996). Decision quality using ranked attribute weights. Management Science 42 (11): 1515-1523.

Baykasoğlu A, Gölcük İ (2015). Development of a novel multiple-attribute decision making model via fuzzy cognitive maps and hierarchical fuzzy TOPSIS. Information Sciences 301: 75-98.

Belton V, Stewart TJ (2002). Multiple criteria decision analysis: an integrated approach. Kluwer Academic, Boston.

Bottomley PA, Doyle JR (2001). A comparison of three weight elicitation methods: Good, 
better, and best. Omega 29 (6): 553-560.

Butler JC, Jia JM, Dyer J (1997). Simulation techniques for the sensitivity analysis of multi-criteria decision models. European Journal of Operational Research 103 (3): 531-546.

Butler JC, Morrice DJ, Mullarkey PW (2001). A multiple attribute utility theory approach to ranking and selection. Management Science 47 (6): 800-816.

Chen TY (2014a). A PROMETHEE-based outranking method for multiple criteria decision analysis with interval type-2 fuzzy sets. Soft Computing 18 (5): 923-940.

Chen TY (2014b). An ELECTRE-based outranking method for multiple criteria group decision making using interval type-2 fuzzy sets. Information Sciences 263 (3): 1-21.

Chen TY, Li CH (2010). Determining objective weights with intuitionistic fuzzy entropy measures: A comparative analysis. Information Science 180 (21): 4207-4222.

Chen TY, Li CH (2011). Objective weights with intuitionistic fuzzy entropy measures and computational experiment analysis. Applied Soft Computing 11 (8): 5411-5423.

Chin KS, Fu C, Wang YM (2015). A method of determining attribute weights in evidential reasoning based on incompatibility among attributes. Computers \& Industrial Engineering 87: $150-162$.

Choo EU, Wedley WC (1985). Optimal criterion weights in repetitive multicriteria decision-making. Journal of the Operational Research Society 36: 983-992.

Corrente S, Greco S, Słowiński R (2016). Multiple criteria hierarchy process for ELECTRE Tri methods. European Journal of Operational Research 252 (1): 191-203.

Corrente S, Greco S, Słowiński R (2017). Handling imprecise evaluations in multiple criteria decision aiding and robust ordinal regression by n-point intervals. Fuzzy Optimization and Decision Making 16: 127-157.

Deng H, Yeh CH, Willis RJ (2000). Inter-company comparison using modified TOPSIS with objective weights. Computers \& Operations Research 27 (10): 963-973.

Diakoulaki D, Mavrotas G, Papayannakis L (1995). Determining objective weights in multiple criteria problems: The critic method. Computers \& Operations Research 22 (7): 763-770.

Doyle JR, Green RH, Bottomley PA (1997). Judging relative importance: Direct rating and point allocation are not equivalent. Organization Behavior and Human Decision Processes 70 (1): 65-72.

Fan ZP, Ma J, Zhang Q (2002). An approach to multiple attribute decision making based on fuzzy preference information on alternatives. Fuzzy Sets and Systems 131 (1): 101-106.

Fischer GW (1995). Range sensitivity of attribute weights in multiattribute value models. Organizational behavior and human decision processes 62 (3): 252-266.

Fu C, Wang YM (2015). An interval difference based evidential reasoning approach with 
unknown attribute weights and utilities of assessment grades. Computers \& Industrial Engineering 81: 109-117.

Fu C, Xu DL (2016). Determining attribute weights to improve solution reliability and its application to selecting leading industries. Annals of Operations Research 245 (1): 401-426.

Fu C, Xu DL, Yang SL (2016). Distributed preference relations for multiple attribute decision analysis. Journal of the Operational Research Society 67: 457-473.

Fu C, Yang JB, Yang SL (2015). A group evidential reasoning approach based on expert reliability. European Journal of Operational Research 246 (3): 886-893.

He YH, Guo HW, Jin MZ, Ren PY (2016). A linguistic entropy weight method and its application in linguistic multi-attribute group decision making. Nonlinear Dynamics 84 (1): 399-404.

Horowitz I, Zappe C (1995). The linear programming alternative to policy capturing for eliciting criteria weights in the performance appraisal process. Omega 23 (6): 667-676.

Hwang CL, Yoon K (1981). Multiple attribute decision-making: methods and applications. Springer, Berlin.

Jiang ZZ, Zhang RY, Fan ZP, Chen XH (2015). A fuzzy matching model with Hurwicz criteria for one-shot multi-attribute exchanges in E-brokerage. Fuzzy Optimization and Decision Making 14: 77-96.

Kadziński M, Corrente S, Greco S, Słowiński R (2014). Preferential reducts and constructs in robust multiple criteria ranking and sorting. OR Spectrum 36: 1021-1053.

Keeney RL (2002). Common mistakes in making value trade-offs. Operations Research 50 (6): 935-945.

Keeney RL, Raiffa H (1993). Decisions with multiple objectives: preference and value tradeoffs. Cambridge University Press, New York.

Kleine A (1999). Decisions with uncertain alternatives. OR Spektrum 21: 315-329.

Kotz S, Johnson NL (1982). Encyclopedia of statistical sciences. Wiley, New York.

Lan JB, Chen YW, Ning MY, Wang ZX (2015). A new linguistic aggregation operator and its application to multiple attribute decision making. Operations Research Perspectives 2: 156-164.

Ma J, Fan ZP, Huang LH (1999). A subjective and objective integrated approach to determine attribute weights. European Journal of Operational Research 112 (2): 397-404.

Madjid T, Reza KM, Francisco JS, Elahe RD (2016). An extended VIKOR method using stochastic data and subjective judgments. Computers \& Industrial Engineering 97: 240-247.

Miłosz K, Krzysztof C (2016). Integrated framework for preference modeling and robustness analysis for outranking-based multiple criteria sorting with ELECTRE and PROMETHEE. 
Information Sciences 352-353: 167-187.

Nikolsky SM (1977). A course of mathematical analysis. Mir Publishers, Moscow.

Pei Z (2013). Rational decision making models with incomplete weight information for production line assessment. Information Sciences 222: 696-716.

Qin JD, Liu XW, Pedrycz W (2015). An extended VIKOR method based on prospect theory for multiple attribute decision making under interval type-2 fuzzy environment. Knowledge-Based Systems 86: 116-130.

Rao RV, Patel BK, Parnichkun M (2011). Industrial robot selection using a novel decision making method considering objective and subjective preferences. Robotic and Autonomous Systems, 59 (6): 367-375.

Roberts R, Goodwin P (2002). Weight approximations in multi-attribute decision models. Journal of Multi-Criteria Decision Analysis 11 (6): 291-303.

Saaty TL (1977). A scaling method for priorities in hierarchical structures, Journal of Mathematical Psychology 15 (3) (1977) 234-281.

Şahin R, Liu P. Maximizing deviation method for neutrosophic multiple attribute decision making with incomplete weight information. Neural Computing and Applications (7): 1-13.

Shirland LE, Jesse RR, Thompson RL, Iacovou CL (2003). Determining attribute weights using mathematical programming Omega 31 (6): 423-437.

Takeda E, Cogger KO, Yu PL (1987). Estimating criterion weights using eigenvectors: a comparative study. European Journal of Operational Research 29 (3): 360-369.

Wakker PP, Jansen SJT, Stiggelbout AM (2004). Anchor levels at a new tool for the theory and measurement of multiattribute utility. Decision Analysis 1 (4): 217-234.

Wang YM (1998). Using the method of maximizing deviations to make decision for multi-indices. System Engineering and Electronics 20 (7): 24-26, 31.

Wang TR, Liu J, Li JZ, Niu CH (2016). An integrating OWA-TOPSIS framework in intuitionistic fuzzy settings for multiple attribute decision making. Computers \& Industrial Engineering 98: 185-194.

Wang YM, Luo Y (2010). Integration of correlations with standard deviations for determining attribute weights in multiple attribute decision making. Mathematical and Computer Modelling 51 (1-2): 1-12.

Wang YM, Parkan C (2006). A general multiple attribute decision-making approach for integrating subjective and objective information. Fuzzy Sets and Systems 157 (10): $1333-1345$.

Wang YM, Yang JB, Xu DL (2006a). Environmental impact assessment using the evidential reasoning approach. European Journal of Operational Research 174 (3): 1885-1913. 
Wang YM, Yang JB, Xu DL, Chin KS (2006b). The evidential reasoning approach for multiple attribute decision analysis using interval belief degrees. European Journal of Operational Research 175 (1): 35-66.

Winston W (2011). Operations research: applications and algorithms. Tsinghua University Press, Beijing.

Xu DL (2012). An introduction and survey of the evidential reasoning approach for multiple criteria decision analysis. Annals of Operations Research 195 (1): 163-187.

Yang JB (2001). Rule and utility based evidential reasoning approach for multiattribute decision analysis under uncertainties. European Journal of Operational Research 131 (1): 31-61.

Yang WE, Ma CQ, Han ZQ, Chen WJ (2016). Checking and adjusting order-consistency of linguistic pairwise comparison matrices for getting transitive preference relations. OR Spectrum 38: 769-787.

Yang JB, Wang YM, Xu DL, Chin KS (2006). The evidential reasoning approach for MADA under both probabilistic and fuzzy uncertainties. European Journal of Operational Research 171 (1): 309-343.

Yang JB, Xu DL (2013). Evidential reasoning rule for evidence combination. Artificial Intelligence 205: 1-29.

Zhang MJ, Wang YM, Li LH, Chen SQ (2017). A general evidential reasoning algorithm for multi-attribute decision analysis under interval uncertainty. European Journal of Operational Research 257 (3): 1005-1015. 